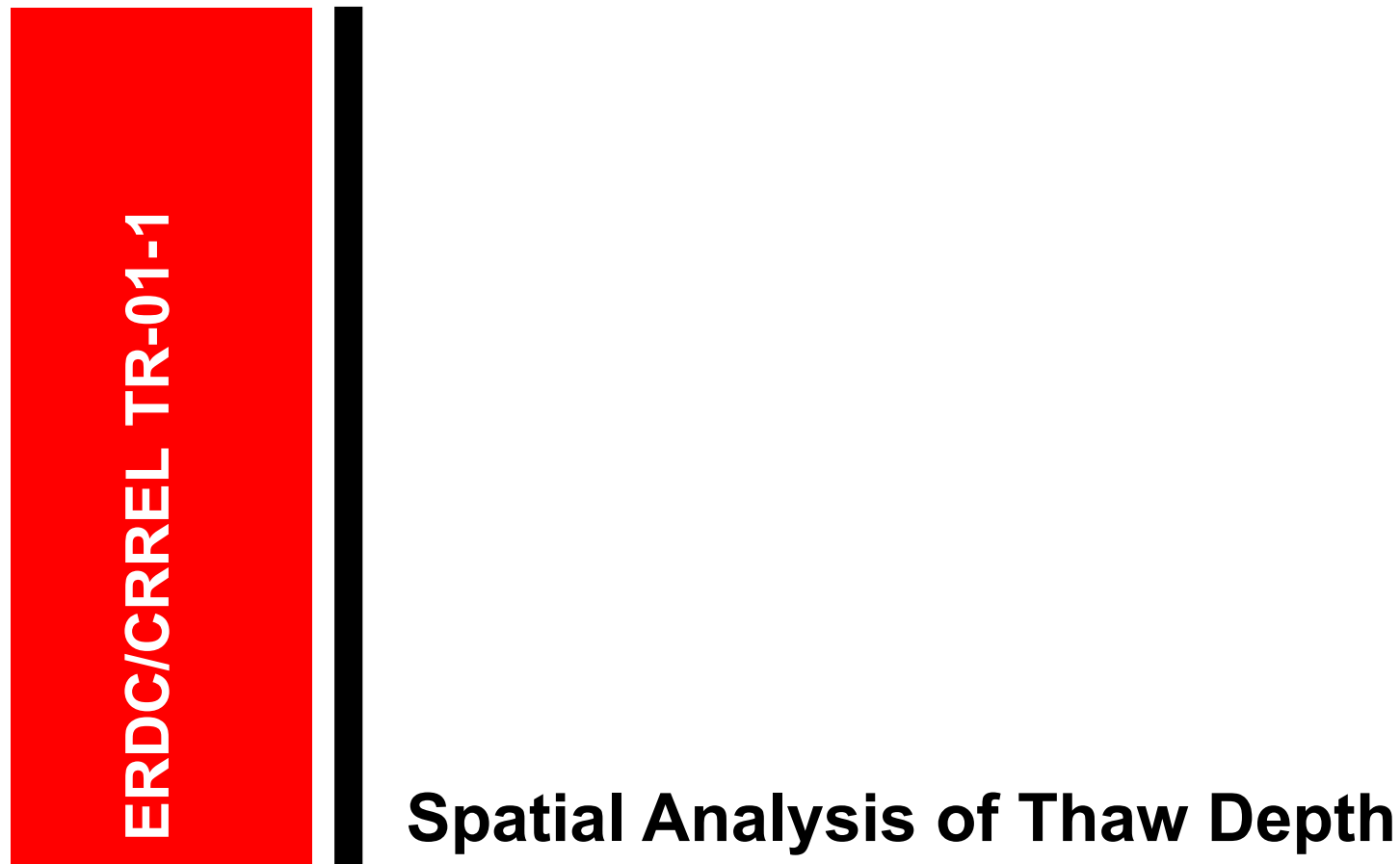

Rosa T. Affleck and Sally A. Shoop

January 2001 


\section{Technical Report ERDC/CRREL TR-01-1}

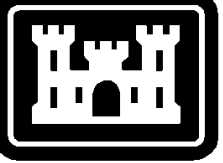

US Army Corps

of Engineers ${ }_{\circledast}$

Cold Regions Research \&

Engineering Laboratory

\section{Spatial Analysis of Thaw Depth}

Rosa T. Affleck and Sally A. Shoop

January 2001 
Abstract: Statistical and spatial analyses were performed on existing thaw-depth data sets from a variety of climatic and terrain conditions to determine the variability of thaw. These data include permafrost sites in Alaska, temperate sites in the continental United States in Minnesota and Wisconsin, and a large-scale, controlled test section with no solar input in the Frost Effects Research
Facility (FERF) at the Cold Regions Research and Engineering Laboratory (CRREL) in Hanover, New Hampshire. Results can be used to spatially distribute soil properties based on point data or onedimensional models, or to populate sparse data sets with terrain properties. They are also useful for analysis of impact of thaw distribution on predictive models, such as for predicting vehicle mobility.

How to get copies of CRREL technical publications:

Department of Defense personnel and contractors may order reports through the Defense Technical Information Center:

DTIC-BR SUITE 0944

8725 JOHN J KINGMAN RD

FT BELVOIR VA 22060-6218

Telephone (800) 225-3842

E-mail help@dtic.mil msorders@dtic.mil

WWW http://www.dtic.mil/

All others may order reports through the National Technical Information Service:

NTIS

5285 PORT ROYAL RD

SPRINGFIELD VA 22161

Telephone (703) 487-4650

(703) 487-4639 (TDD for the hearing-impaired)

E-mail_orders@ntis.fedworld.gov

WWW http://www.ntis.gov/index.html

A complete list of all CRREL technical publications is available from USACRREL (CEERD-IM-HL)

72 LYME RD

HANOVER NH 03755-1290

Telephone (603) 646-4338

E-mail erhoff@crrel.usace.army.mil

For information on all aspects of the Cold Regions Research and Engineering Laboratory, visit our World Wide Web site:

http://www.crrel.usace.army.mil 


\section{PREFACE}

This report was prepared by Rosa T. Affleck, Research Civil Engineer, Civil Engineering Research Division, U.S. Army Cold Regions Research and Engineering Laboratory (CRREL), Engineer Research and Development Center (ERDC), Hanover, New Hampshire, and by Sally A. Shoop, Research Civil Engineer, Applied Research Division, CRREL.

The authors thank Professor Frederick Nelson of the University of Delaware for sharing the North Slope thaw-depth data sets; the National Snow and Ice Data Center for making the Alaska data accessible; and Dr. Brenton Sharrat of North Central Soil Conservation Research Laboratory, U.S. Department of Agriculture, for his data.

The authors also thank Dr. Matthew Sturm of CRREL for his guidance and insight on their analysis, and thank Dr. George Mason, Geotechnical Lab, ERDC, and Dr. Mary Albert and Dr. Matthew Sturm of CRREL for providing technical comments and for reviewing this report.

Funding for this work was provided by DA Project AT42-CS-M10, work unit Spatial Variability of Freeze-Thaw for Trafficability.

This publication reflects the personal views of the authors and does not suggest or reflect the policy, practices, programs, or doctrine of the U.S. Army or Government of the United States. The contents of this report are not to be used for advertising or promotional purposes. Citation of brand names does not constitute an official endorsement or approval of the use of such commercial products. 


\section{CONTENTS}

Preface

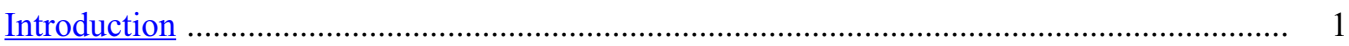

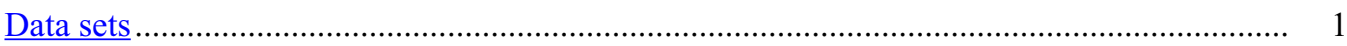

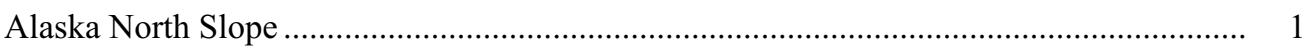

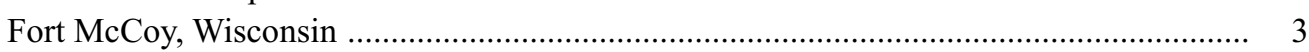

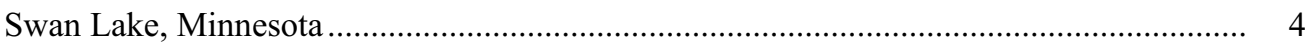

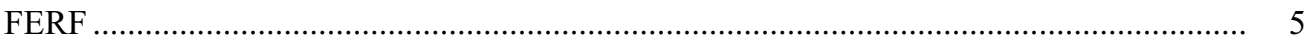

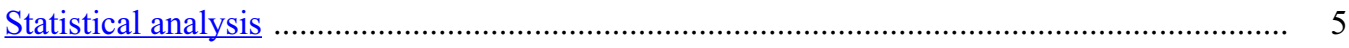

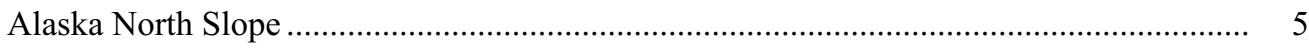

Fort McCoy, Wisconsin ......................................................................................... 7

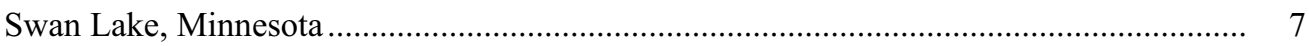

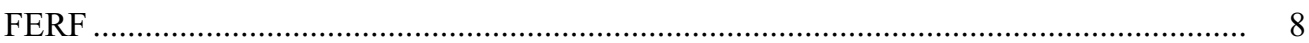

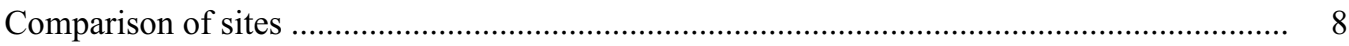

Spatial statistics

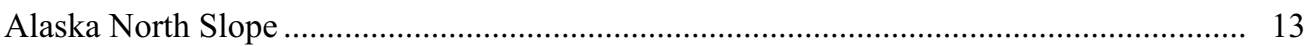

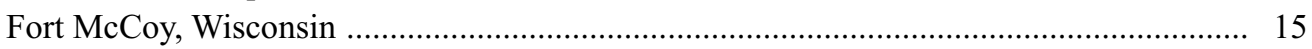

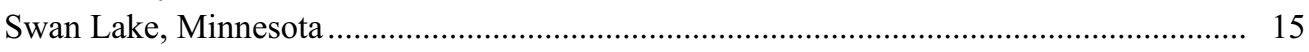

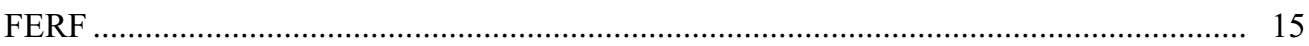

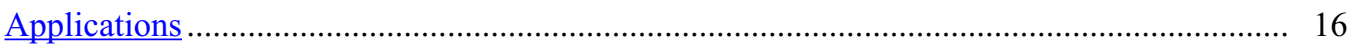

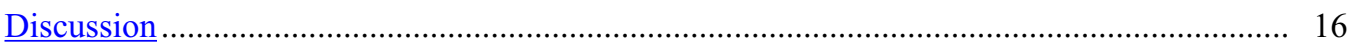

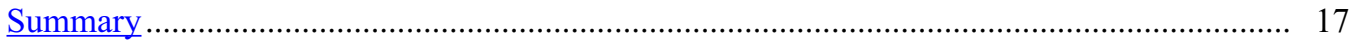

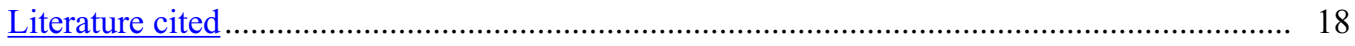

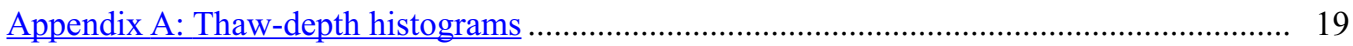

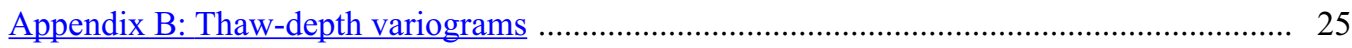

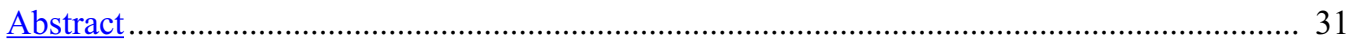

\section{ILLUSTRATIONS}

Figure

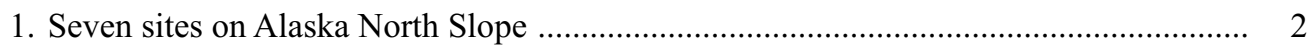

2. Sampling grid for the seven Alaska sites ..................................................................... 3

3. Location map for Minnesota and Wisconsin sampling sites .......................................... 4

4. Sampling grid for Fort McCoy .................................................................................. 4

5. Sampling grid, site contour, and soil map for Swan Lake Watershed ............................ 4

6. FERF grid sampling patterns ................................................................................ 5

7. North Slope thaw-depth histogram …………………............................................... 7

8. Fort McCoy thaw-depth histogram ………………........................................... 8

9. Typical histograms, Swan Lake ………………….............................................. 8 
Figure

10. Elevation versus thaw depth at Swan Lake .......................................................... 9

11. FERF thaw-depth distribution on two sampling events ........................................... 10

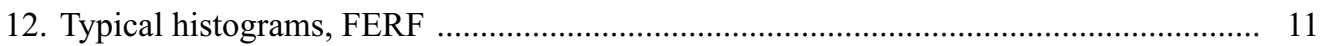

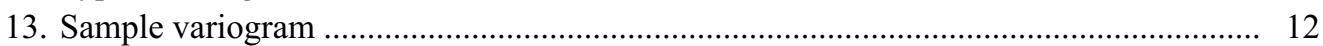

14. Three most commonly used transition models ........................................................ 12

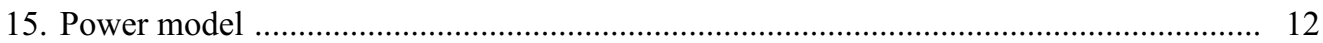

16. Variogram plots for Alaska North Slope .................................................................. 13

17. Fort McCoy variogram ................................................................................... 15

18. Swan Lake variogram ................................................................................... 15

19. Typical variogram plots of FERF data sets ............................................................ 16

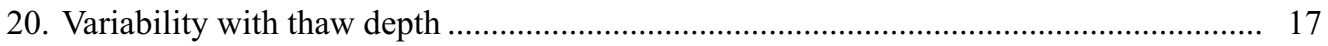

\section{TABLES}

Table

1. Locations of the seven grid sites on Alaska North Slope .......................................... 2

2. Thaw-depth coefficient-of-variation distribution for all sites ................................... 5

3. Statistical and spatial correlation analysis summary for all thaw-depth data sets .......... 6 


\title{
Spatial Analysis of Thaw Depth
}

\author{
ROSA T. AFFLECK AND SALLY A. SHOOP
}

\section{INTRODUCTION}

The objective of this work was to develop an approach to characterizing the spatial variability of thawing soil. Results can then be applied to spatially distribute soil properties based on point data or onedimensional models, or to fill sparse data sets with terrain properties. Results are also useful for probabilistic analysis of the impact of the input distribution on the confidence of predictive models, such as for predicting vehicle mobility or surface runoff. Thaw depth was used as the variable of interest because of its clear impact on terrain strength and hydrology. Other soil variables can be analyzed similarly. A comparison among these data sets also indicates the impact of other terrain parameters, such as vegetation or radiation, on the thaw variability for a particular terrain unit.

A search and review of existing data sets having spatial thaw measurements yielded four major data sets suitable for analysis. These data cover a variety of climatic and terrain conditions, including permafrost sites in Alaska, temperate sites in Minnesota and Wisconsin, and a large-scale, controlled test section with no solar input in the Frost Effects Research Facility (FERF) at the Cold Regions Research and Engineering Laboratory (CRREL) in Hanover, New Hampshire. Each of these data sets is described in detail below.

Thaw is a complicated process, influenced by the surface energy balance, terrain, and soil properties at each point. Thaw depth is the thickness of the thawed layer from the surface to an underlying frozen layer, which typically occurs when temperature is above freezing in spring. Terrain with a thawed layer can be very saturated due to snowmelt, rain, and water drawn to the soil during the freezing process. Slopes (aspect and degree), types of vegetation, and soil properties affect the variation on thaw depth. With all these variable con- ditions, one would expect a very high degree of heterogeneity. The basic question is to define the spatial variability of depth of thaw and analyze the site's specific effects on this variability. The Alaska North Slope data sets are from areas of continuous permafrost where the underlying frozen layer will remain year-round. The bulk of the measurements were taken at the end of the summer when the thaw had penetrated to the maximum depth. The other sites are located in areas without permafrost where all frost will eventually be removed as the bottom of the frozen layer meets with a thawed layer by late spring or early summer. The data sets were collected over a wide range of spacing and scales, all of which affect the resulting spatial analysis. This is an initial effort to develop variation of thaw depth for a variety of conditions, but this work excludes the impact of surface energy balance and climatic conditions on the thaw variability.

\section{DATA SETS}

\section{Alaska North Slope}

Thaw depth (active-layer thickness) data on Alaska North Slope were collected for Arctic climate-change research headed by Dr. Frederick E. Nelson for Arctic System Science/Land-Atmosphere-Ice Interactions (ARCSS/LAII) sponsored by the National Science Foundation (Nelson et al. 1997). The National Snow and Ice Data Center (NSIDC) managed and archived these data sets.

Permafrost underlies the area. Nelson et al. (1997) used Geographic Information Systems (GIS) to map and develop an integrated response of thaw depth using air temperature, vegetation, soils and soil moisture, and solar radiation for these sites. Figure 1 shows the locations of the seven sites where thaw depth was meas- 


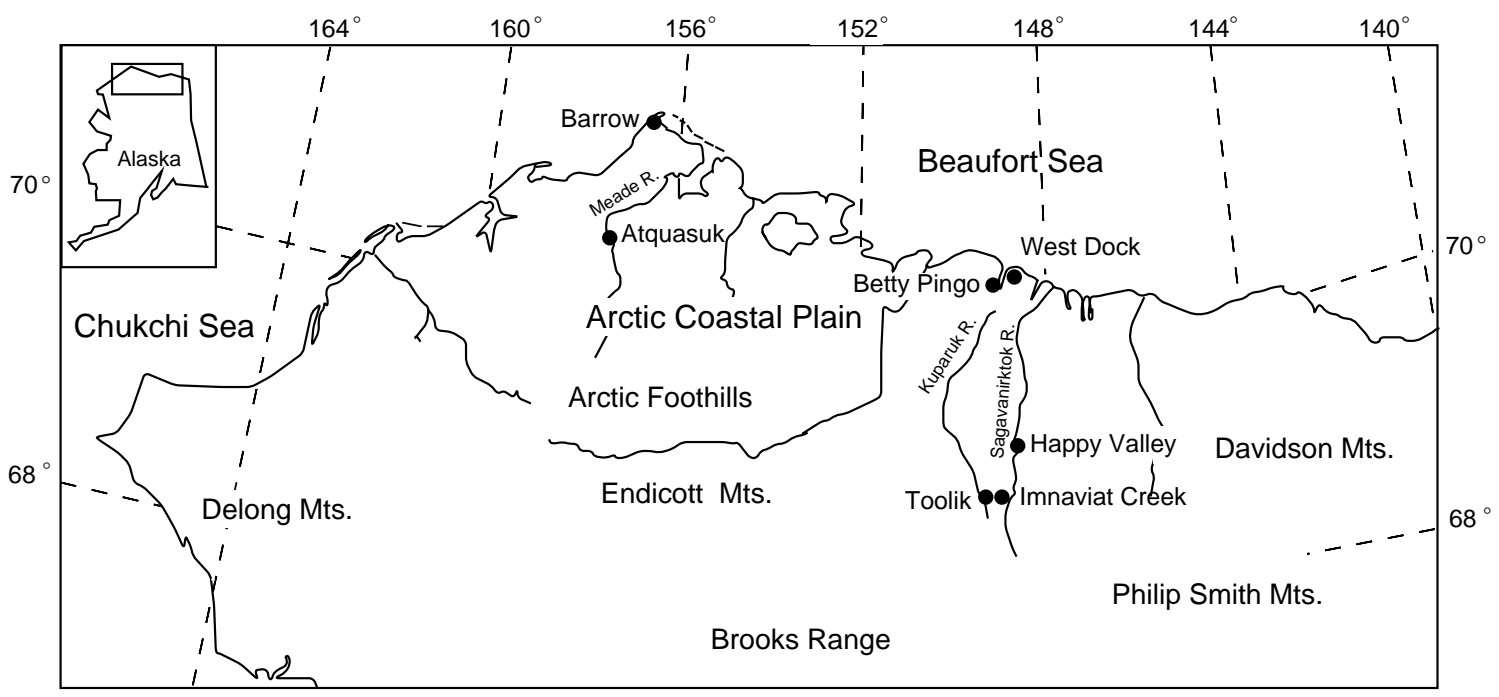

Figure 1. Seven sites on Alaska North Slope.

\begin{tabular}{|c|c|c|c|c|c|}
\hline \multirow[b]{2}{*}{ Site } & \multirow{2}{*}{$\begin{array}{c}\text { Terrain } \\
\text { description }\end{array}$} & \multicolumn{2}{|c|}{ Coordinates* } & \multicolumn{2}{|c|}{$\begin{array}{c}\text { Universal Transverse } \\
\text { Mercator (UTM) } \\
\text { Zone 6 }{ }^{\dagger} \\
\end{array}$} \\
\hline & & Latitude & Longitude & Northing & Easting \\
\hline Atquasuk & Coastal & $70^{\circ} 27^{\prime} \mathrm{N}$ & $157^{\circ} 24^{\prime} \mathrm{W}$ & 7816500 & 559200 \\
\hline Barrow & Coastal & $71^{\circ} 19^{\prime} \mathrm{N}$ & $156^{\circ} 36^{\prime} \mathrm{W}$ & 7913100 & 585700 \\
\hline Betty Pingo & Coastal & $70^{\circ} 17^{\prime} \mathrm{N}$ & $148^{\circ} 52^{\prime} \mathrm{W}$ & 7797700 & 428900 \\
\hline Happy Valley & Foothill & $69^{\circ} 06^{\prime} \mathrm{N}$ & $148^{\circ} 30^{\prime} \mathrm{W}$ & 7671500 & 426000 \\
\hline Imnaviat Creek & Foothill & $68^{\circ} 30^{\prime} \mathrm{N}$ & $149^{\circ} 30^{\prime} \mathrm{W}$ & 7612300 & 405600 \\
\hline Toolik Lake & Foothill & $68^{\circ} 37^{\prime} \mathrm{N}$ & $149^{\circ} 36^{\prime} \mathrm{W}$ & 7613900 & 393500 \\
\hline West Dock & Coastal & $70^{\circ} 22^{\prime} \mathrm{N}$ & $148^{\circ} 34^{\prime} \mathrm{W}$ & 7807300 & 440800 \\
\hline
\end{tabular}

ured in July and August 1995. The coordinates of the sites are given in Table 1.

Thaw depth was collected at 100-m intervals on 1- by 1-km grid (Fig. 2). Thaw depths were not measured where grid points intersected lakes, rocks, or roads. Thaw depth was measured using a rigid metal rod pushed into the ground to refusal.

Atquasuk soils are mostly sand to loamy sand. The soil landforms in Atquasuk are grouped into three categories: moderately well drained, where the soils have coarse texture and low concentration of organic matter; somewhat poorly drained, where the water table is below the surface; and very poorly drained, where the soils have considerable amounts of organic matter and the water table is at or above the surface (Everett 1980). Everett classified the soils as Pergelic Cryaquepts (covers most of the area), Pergelic Cryohemists and Cryosapriest, Pergelic Cryopsamments, and Pergelic Cryofluents. The Atquasuk area is considered fairly flat meadow terrain. Tussock tundra is the most common type of vegetation in the area. A detailed description of the vegetation near Atquasuk is provided in Komarkova and Webber (1980).

Barrow, the northernmost point in Alaska, is dominated by wet and acid soils. As described in Brown et al. (1980), the soils in the area are formed on flat to gently sloping topography under cold and moist conditions and consist of a considerable amount of organic matter. These soils have a three-layer morphology: an organic-rich surface horizon; a horizon of silty clay to silty loam textured mineral soil with variable amounts of organics; and an underlying horizon of a perennially frozen organic-rich layer. The vegetation of the general area in Barrow consists of sedge meadows and mosses (Brown et al. 1980).

Betty Pingo is located in a wetland terrain with minimal topographic relief (Hinzman et al. 1998). The soil in Betty Pingo consists of silt loam soil mixed with a 


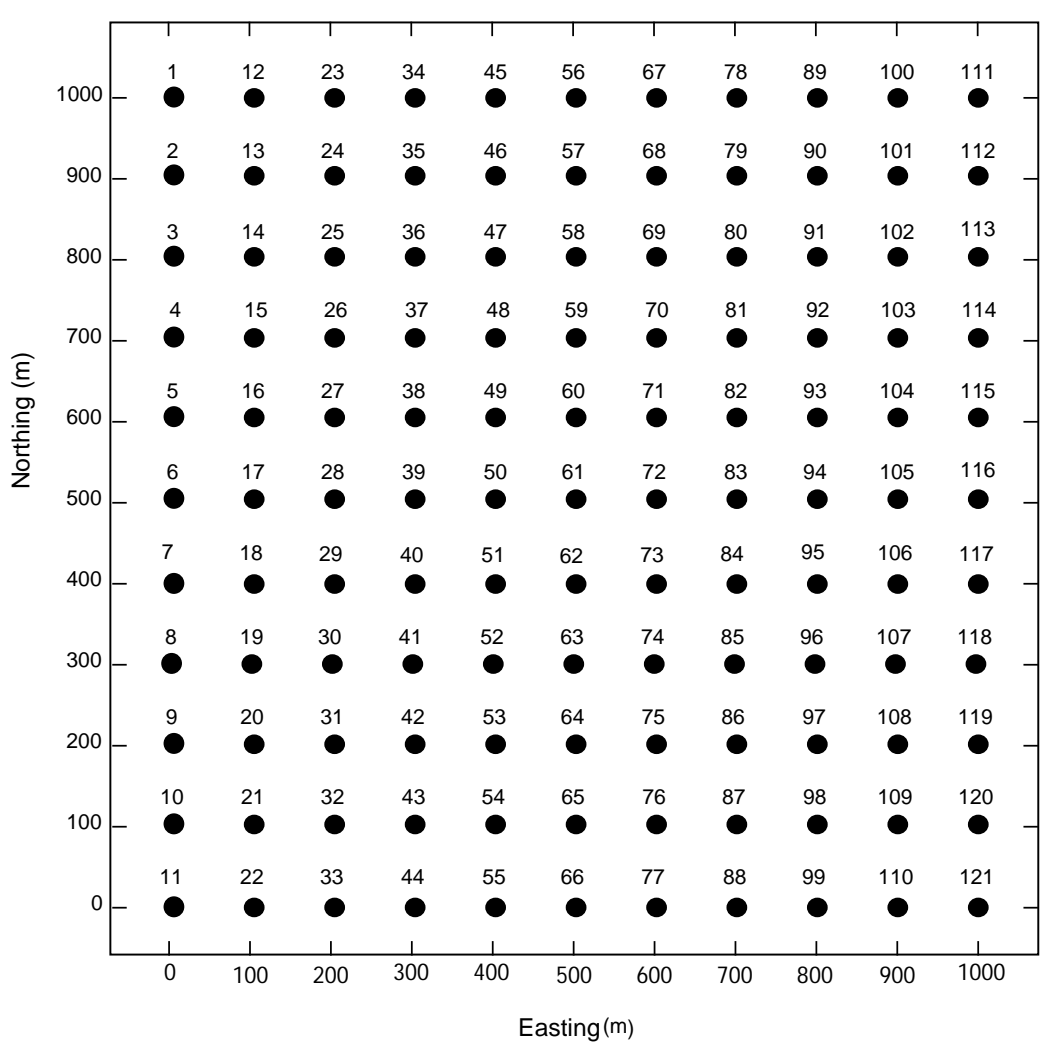

Figure 2. Sampling grid for the seven Alaska sites.

substantial amount of organic materials, and is classified as Euic Pergelic Cryosapriest (Ping et al. 1994). The vegetation includes sedge, shrub, lichens, and mosses.

Happy Valley is on a slight slope with a western aspect. The soil is classified as a fine-loamy, mixed Pergelic Cryaquept, which is composed of silt loam with organic materials and a layer of peat on top (Ping et al. 1994). Area vegetation includes grasses, shrubs, lichens, and mosses.

The landform at Imnaviat Creek is mostly a hill slope (more than 20\% slope), with a portion of the area in a basin. The aspect of the slope ranges from west to north. Soils of Imnaviat Creek consist of about $10 \mathrm{~cm}$ of live and dead organic material over 5 to $10 \mathrm{~cm}$ of partially decomposed organic material mixed with silt, all over glacial till, and are listed as Histic Pergelic Cryaquepts (Hinzman et al. 1991). Vegetation in Imnaviat consists of mostly water-tolerant plants such as tussock-sedges, mosses associated with lichens, and shrubs such as dwarf birch, alder, and willows (Kane et al. 1994). Tussock-sedges are common on the ridge tops and on slopes, but lacking in the valley bottom. Mosses are dominant in the valley bottom where the environment is wettest.

The Toolik Lake site is contained on a hillslope (up to $20 \%$ slope with an aspect ranging from east to north) on colluvial deposits and a portion of the area is on frozen water (pond). More than half of the area consists of moist acidic tundra (soil $\mathrm{pH}<5.0$ ) dominated by tussock-sedges, dwarf shrubs, and mosses. The remaining area is moist non-acidic (soil $\mathrm{pH}>5.0$ ) and dry acidic tundra vegetation (Walker 1998). The soils in Toolik Lake are classified as a coarse-loamy, mixed Pergelic Cryochrepts composed of layers of peat, loam, and sandy loam (Ping et al. 1994).

West Dock is at an elevation of $3 \mathrm{~m}$ above mean sea level. The soil is composed of layers of peat, loamy sand, and fine sandy loam (Ping et al. 1994) and is classified as coarse-loamy, mixed Pergelic Ruptic-Histic Cryaquept. The vegetation consists of sedge shrubs, mosses, and lichens.

Betty Pingo and West Dock are located in a wetland complex with little topographic relief near Prudhoe Bay and are considered part of the upper Kuparuk River drainage basin (Walker et al. 1980). West Dock, Betty Pingo, Happy Valley, Imnaviat Creek, and Toolik Lake are located on the Kuparuk River drainage basin (Nelson et al. 1997).

\section{Fort McCoy, Wisconsin}

In contrast to the Alaska sites, this site is in a nonpermafrost area. The average freezing season is 117 days and expected frost depth is $0.50 \mathrm{~m}$. Thaw depths were collected on 23 March 1995, at Fort McCoy, Wiscon- 


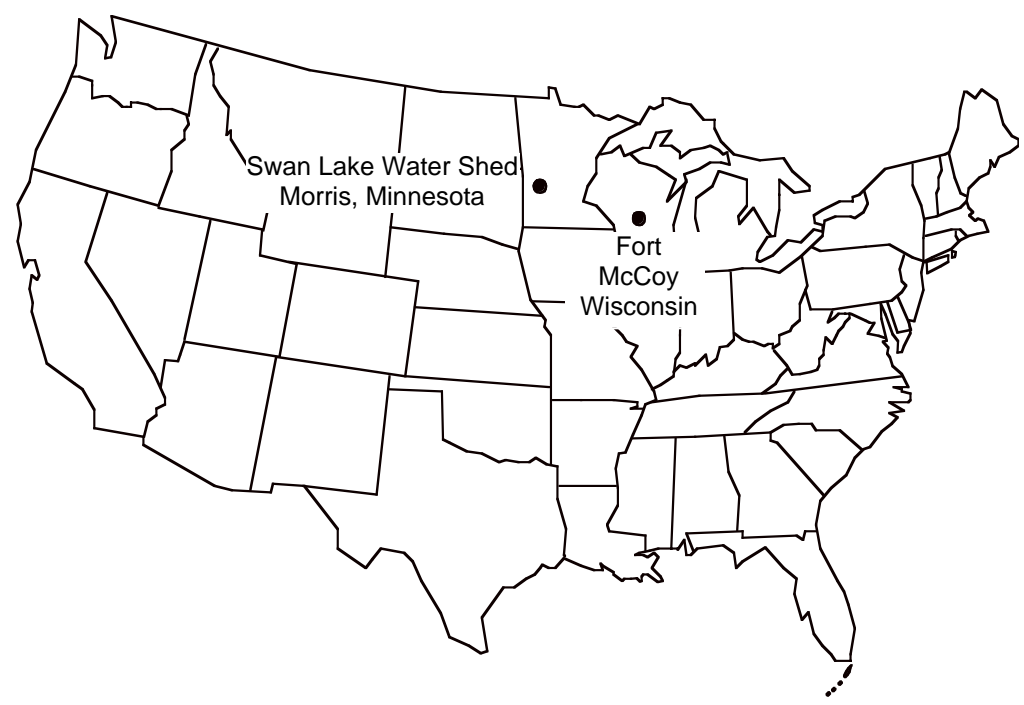

Figure 3. Location map for Minnesota and Wisconsin sampling sites.

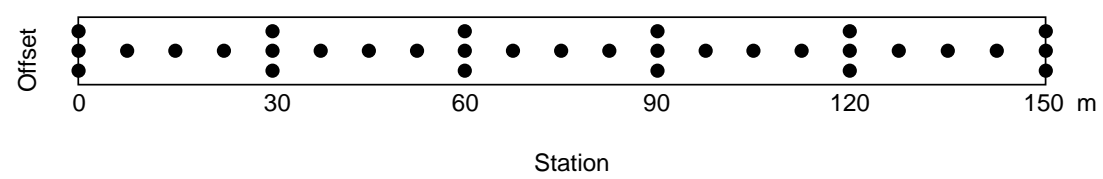

Figure 4. Sampling grid for Fort McCoy.

$\sin \left(44^{\circ} \mathrm{N}, 90^{\circ} \mathrm{W}\right)$, shown in Figure 3, along a narrow 580-m-long trail (Kestler 1996, Kestler et al. 1999). The trail consisted of a saturated, thawing soil layer over frozen ground. Thaw depths were measured at $7.6-\mathrm{m}$ intervals along the trail centerline and at 30.50$\mathrm{m}$ intervals in the right and left wheel paths, which were approximately $1.2 \mathrm{~m}$ off the trail centerline. Figure 4 is the typical sampling pattern. A metal rod was used to determine thaw depth by pushing the rod into the ground until it met resistance and by checking the temperature at this interface.

The soil on this trail was classified as silty sand. The trail water content ranged from 8 to $34 \%$ with an average of $18.6 \%$ and standard deviations of 4.4. The optimum moisture content (moisture of the soil when compacted at maximum density) of the soil mineral ranged from 8.2 to $11.4 \%$. The trail consisted of a thin (0- to $10-$ $\mathrm{cm}$ ) vegetated layer on top of the mineral soil. The percent slope of the terrain ranged from flat to gently sloping (with a maximum of one short section of $10 \%$ slope). Trees were present along the sides of the trail, contributing to variations in shading on the trail surface.

\section{Swan Lake, Minnesota}

Thaw depths were collected on a shallow depression in the Swan Lake watershed (Fig. 3), near Morris, Minnesota $\left(45^{\circ} 41^{\prime} \mathrm{N}, 95^{\circ} 48^{\prime} \mathrm{W}\right)$, by
Dr. Brenton Sharratt of the U.S. Department of Agriculture (USDA), North Central Soil Conservation Research Laboratory (Sharratt et al. 1999). The elliptical depression or prairie pothole was about 2 ha in area

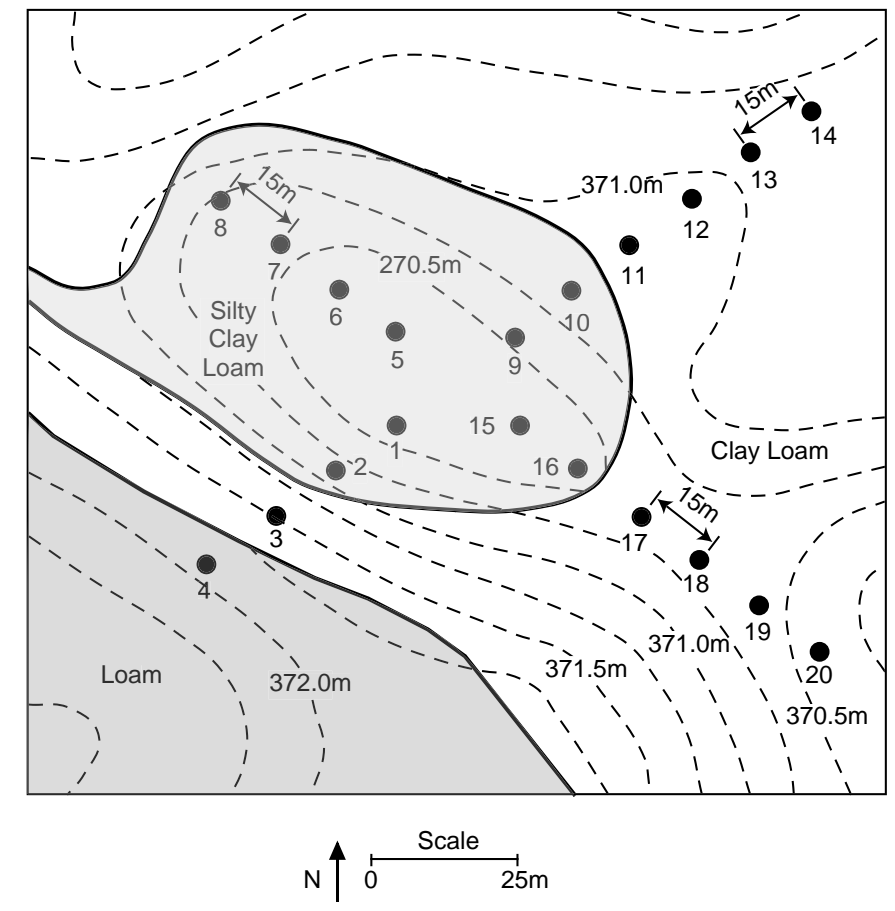

Figure 5. Sampling grid, site contour, and soil map for Swan Lake Watershed. 

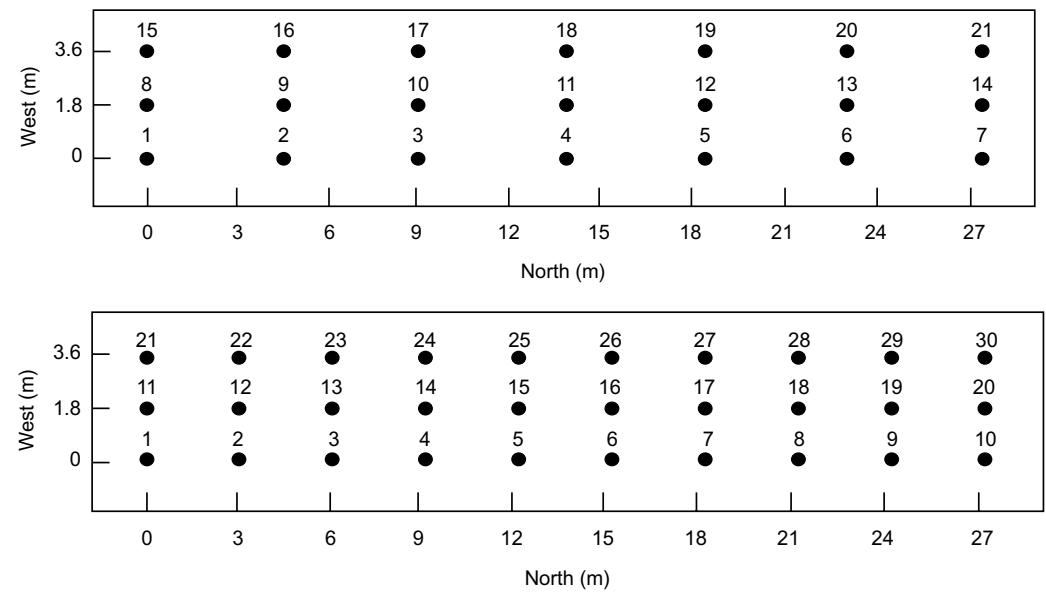

Figure 6. FERF grid sampling patterns.

with $2 \mathrm{~m}$ of relief. The major axis of the depression is oriented NW-SE. Thaw depth measurements were taken along both the major and minor axis (Fig. 5) using frost tubes during spring 1991 and 1992.

The soil types present within the depression included loam, silty clay loam, and clay loam. Wheat was grown on this site in the spring of 1990 and 1991. The depression was chisel-plowed after fall harvest (October) each year. Unlike the Alaska sites, this site is without permafrost. The maximum soil frost depth of this site is 1.2 $\mathrm{m}$, and average freezing period is 130 days.

\section{FERF}

Thaw depths were collected in a controlled and prepared freeze-thaw experiment in the FERF on a homogeneous soil compacted at specified moisture content and density. This site is an indoor, temperaturecontrolled environment that should reflect homogenous soil conditions and eliminates the climatic, terrain, and solar radiation effects of the natural environment. Thaw depths were measured over the 100 -square-meter area by pushing a metal rod into the soil and were verified by digging to the frost layer. Figure 6 shows typical grid spacings used for these measurements. (Some of the data sets were collected on a tighter grid than others.)

The soil type was characterized as silt. The dry density of the soil varied from 1.39 to $1.70 \mathrm{~g} / \mathrm{cm}^{3}$ and the moisture content ranged from 20 to $30 \%$ (optimum water content is $22 \%$ ). The soil's maximum density from the standard proctor test was $1.52 \mathrm{~g} / \mathrm{cm}^{3}$ (Shoop et al. 2000).

\section{STATISTICAL ANALYSIS}

Thaw depths were analyzed to assess the distribution of thaw as well as to determine the spatial effects. The statistical calculations include the average, stan- dard deviation and coefficient of variation (CV). The ratio of standard deviation to the mean, eq 1 , is often used to describe the distribution (i.e., the histogram) (Isaaks and Srivastava 1989). A CV greater than one indicates the presence of some erratic sample values and high variability in the data. A CV less than one indicates low variability in the data set. Histograms of the thaw depth are displayed for each of the data sets.

$$
C V=\frac{\sigma}{m}
$$

where $C V=$ coefficient of variation

$$
\begin{aligned}
\sigma & =\text { standard deviation } \\
m & =\text { mean. }
\end{aligned}
$$

\section{Alaska North Slope}

Representative histograms from each of the sites in Alaska are shown in Figure 7 (all histograms are given in Appendix A). Statistical analysis for each of the thaw depth measurement events for all data sets is given in Tables 2 and 3. As mentioned earlier, there were missing thaw depths on the grid because the point(s) or por-

\begin{tabular}{|c|c|c|}
\hline Sites & CV Range & Average CV \\
\hline Atquasuk, Alaska & $0.4-0.5$ & 0.43 \\
\hline Barrow, Alaska & $0.3-0.5$ & 0.32 \\
\hline Betty Pingo, Alaska & 0.3 & 0.33 \\
\hline Happy Valley, Alaska & $0.2-0.4$ & 0.28 \\
\hline Imnaviat Creek, Alaska & $0.2-0.3$ & 0.25 \\
\hline Toolik Lake, Alaska & $0.3-0.4$ & 0.32 \\
\hline West Dock, Alaska & 0.3 & 0.26 \\
\hline Fort McCoy, Wisconsin & 0.5 & 0.45 \\
\hline Swan Lake, Minnesota & $0.2-0.6$ & 0.39 \\
\hline FERF, Hanover, N.H. & $0.1-0.6$ & 0.21 \\
\hline
\end{tabular}
tion of the grid was located on lakes, standing water, rocks, and roads. Thus code 200 was used for lakes and 


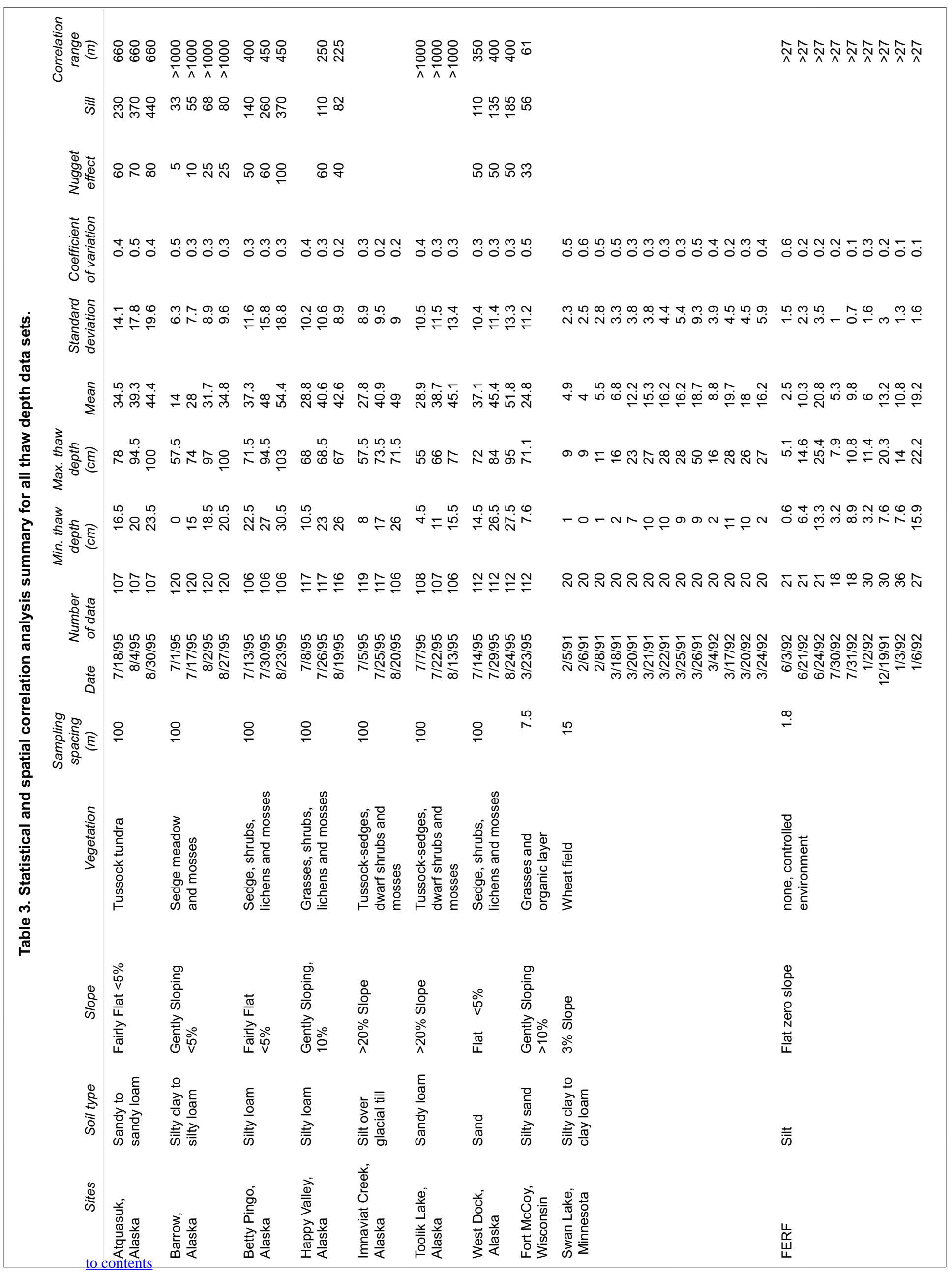



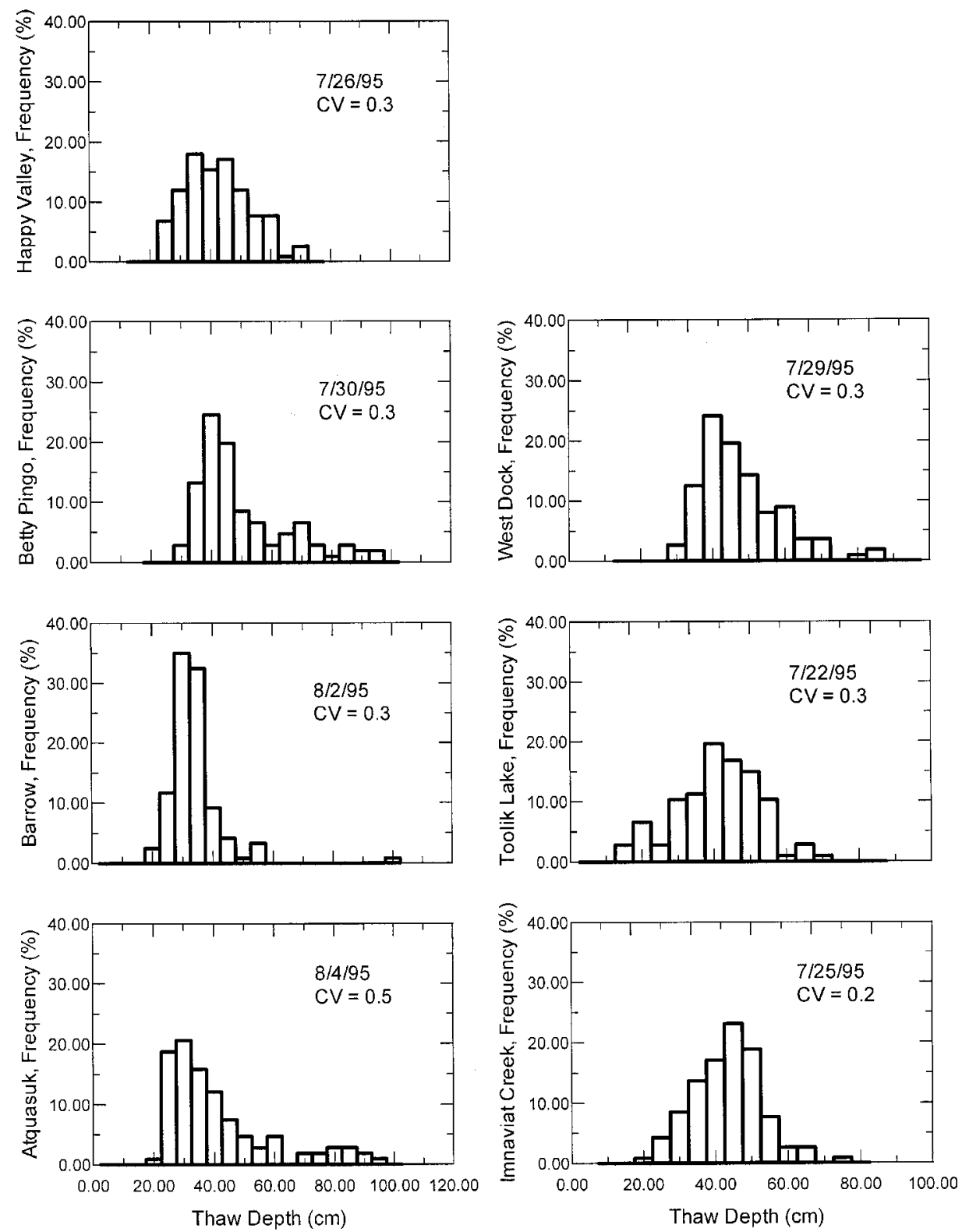

Figure 7. North Slope thaw-depth histogram.

standing water and 300 was used for rocks, gravel, roads, etc. These codes were culled for our analysis. All seven sites have a very low coefficient of variation, ranging from 0.2 to 0.5 , indicating minimum variation in the data sets.

The histograms for Atquasuk, Betty Pingo, and West Dock are somewhat skewed with a long tail of high thaw-depth values. The skewed data sets were located in the coastal areas with relatively flat terrain; however, it is unclear how these factors may have affected the distribution. Thaw depth for Barrow, Happy Valley, Imnaviat Creek, and Toolik Lake more closely resemble a normal distribution. These behaviors are consistent for all data sets for each site (App. A).

\section{Fort McCoy, Wisconsin}

A histogram for thaw depths on the trail at Fort McCoy showed scattered distribution with a wide range and CV of 0.5 as shown in Figure 8. Table 3 shows the minimum and maximum thaw depth. As the data were collected for only one date, no temporal comparisons are possible.

\section{Swan Lake, Minnesota}

The coefficient of variation for the 13 data sets from Swan Lake, Minnesota, varied from 0.2 to 0.6 (Tables 2 and 3). Figure 9 illustrates typical histograms for the data sets and all of the data histograms are shown in A8. The thaw depths showed spread distribution. These 


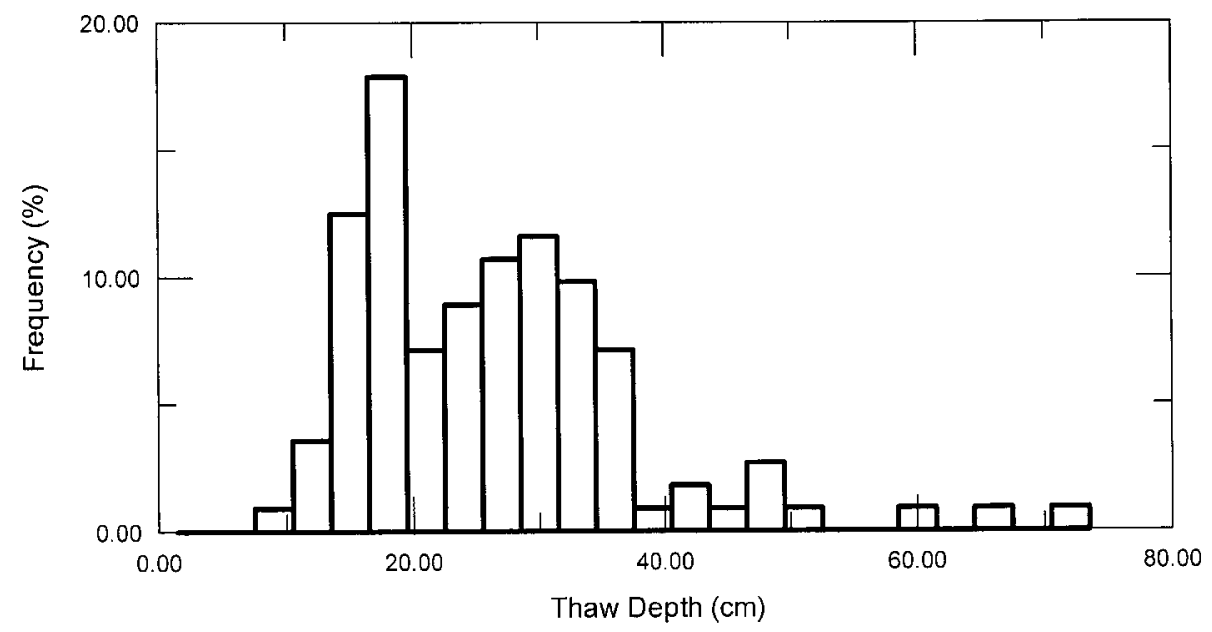

Figure 8. Fort McCoy thaw-depth histogram.

thaw depth variations were due to the influence of variations of solar radiation and topography (slope and aspect). Because of the shallow depression, the southernfacing slope gains more intense sunlight during part of the day while the northernfacing slope gets the self-shadowing effect. Sharrat et al. (1999) mentioned that rapid thawing at location 9 and possibly location 5 occurred when water was present in the center of the depression. The progression of thaw with time is shown in Figure 10, showing anomalous thaws at locations 5, 9, and 20. In general the thaw depth progressed downward evenly with time.

\section{FERF}

The average thaw depth for the FERF data sets ranged from 2.5 to $20.8 \mathrm{~cm}$. Standard deviations ranged from 1 to $3.5 \mathrm{~cm}$ (Tables 2 and 3). For all data sets, the thaw depth is higher at one end of the test basin (Fig. 11). This is true for most of the data sets in the FERF, and is probably due to changes in the air temperature and frost properties at the north end of the test section where the floor of the test basin ramps up toward the building entrance. Figure 12 shows the histograms for three of the thaw events.

\section{COMPARISON OF SITES}

A comparison of variability at each site is given in Table 2. The FERF data sets showed the lowest $\mathrm{CV}$, with an average
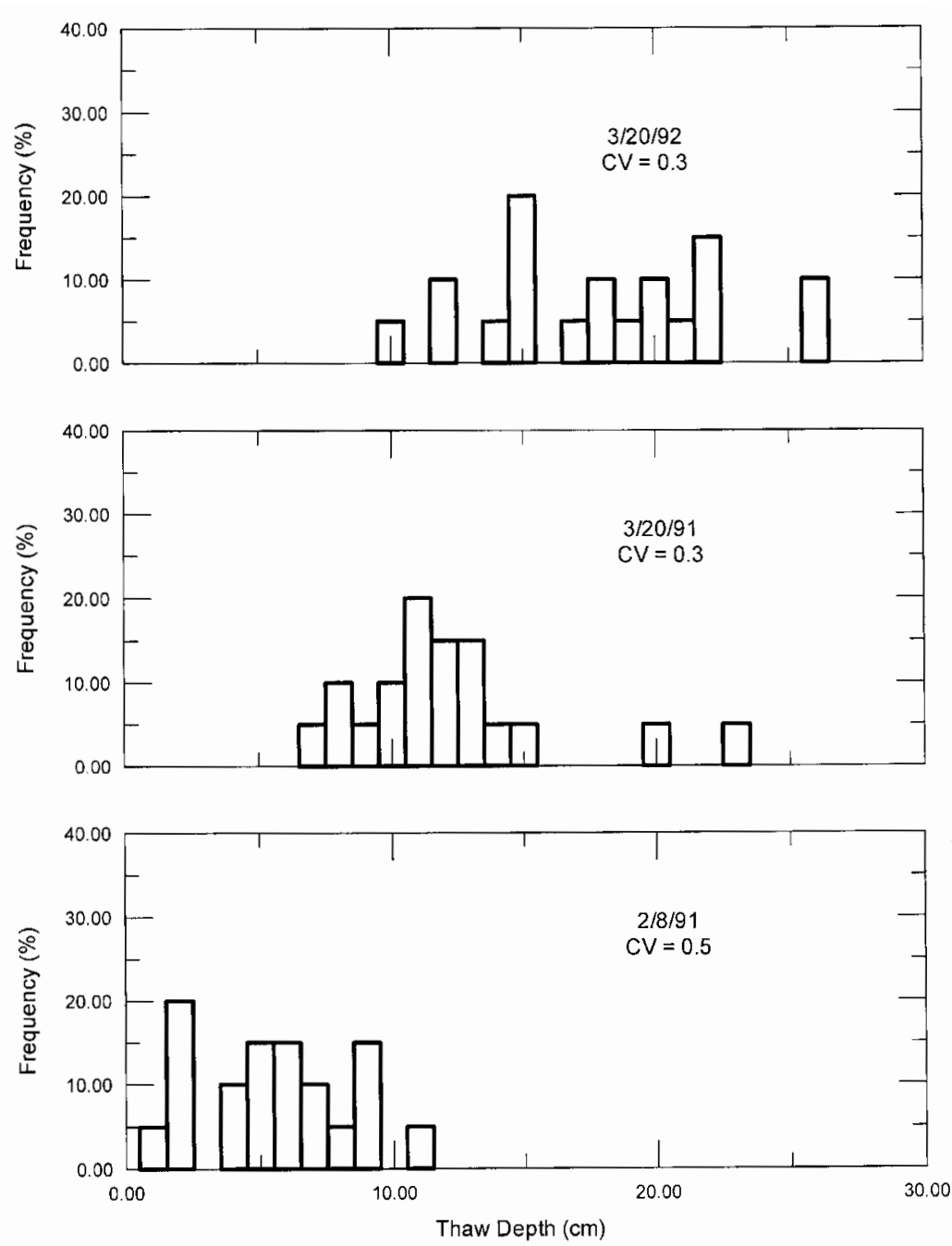

Figure 9. Typical histograms, Swan Lake. 

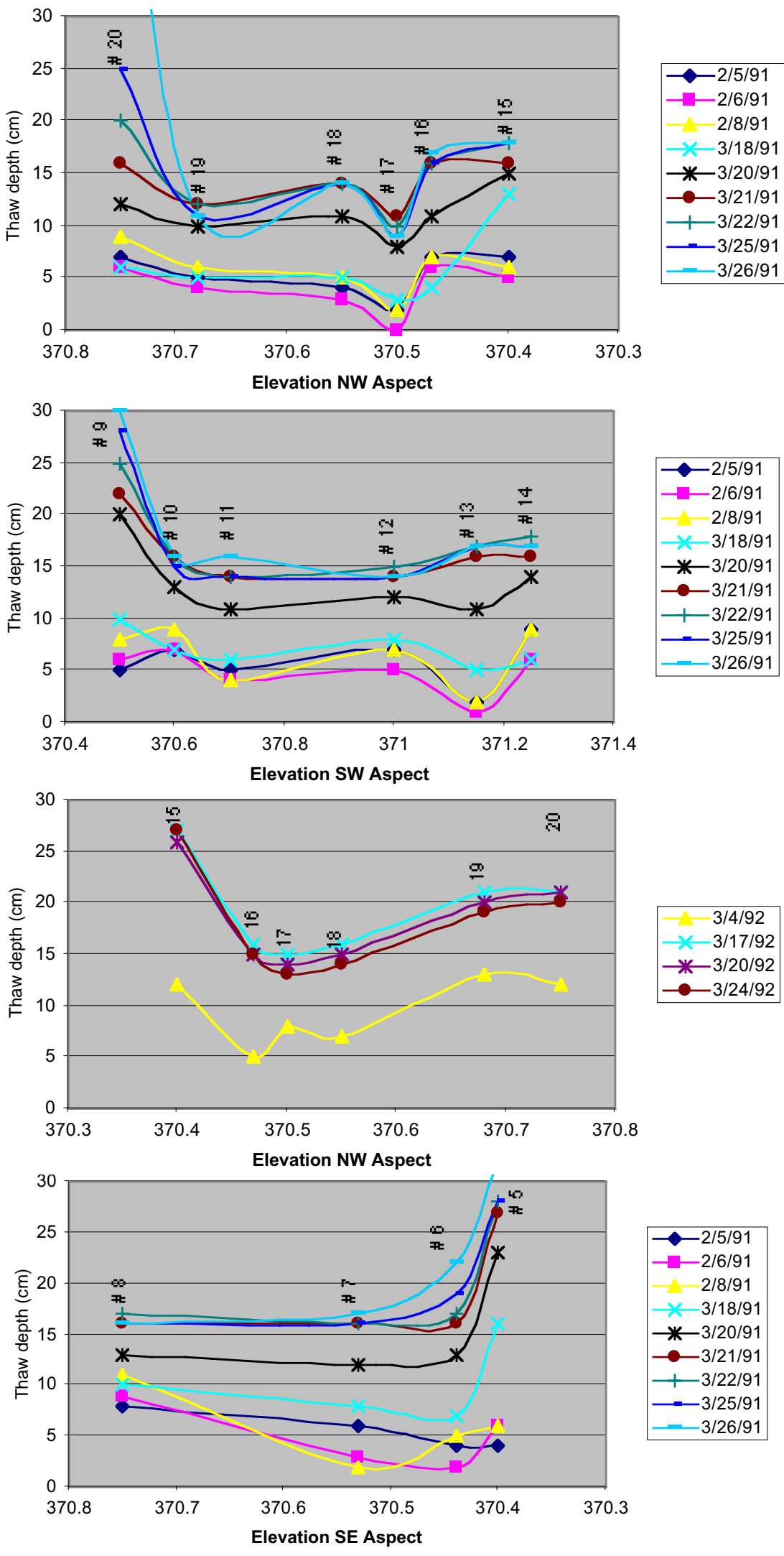

Figure 10. Elevation versus thaw depth at Swan Lake. 


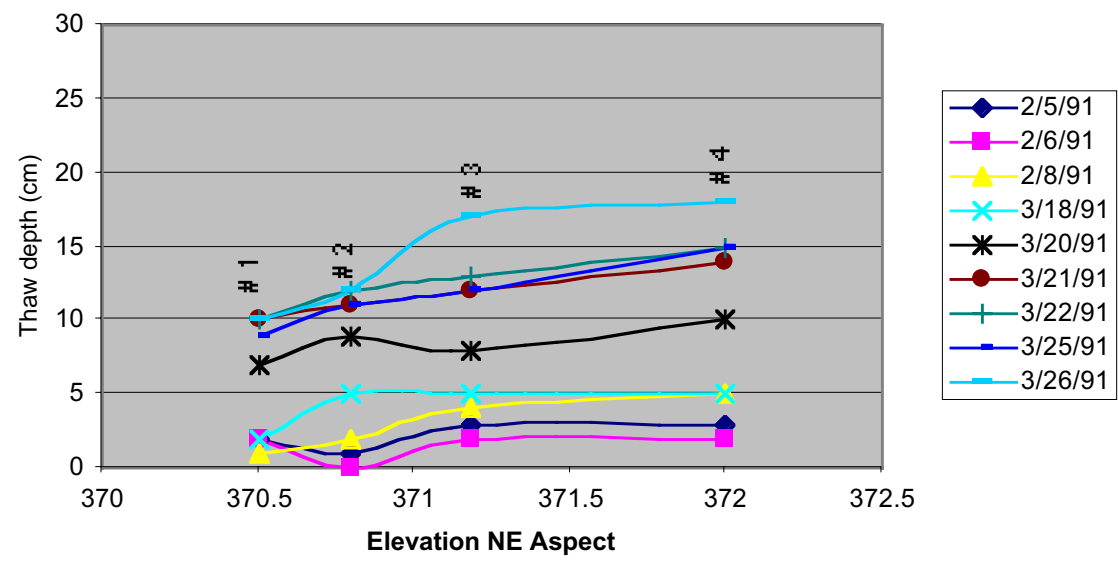

Figure 10 (cont'd). Elevation versus thaw depth at Swan Lake.

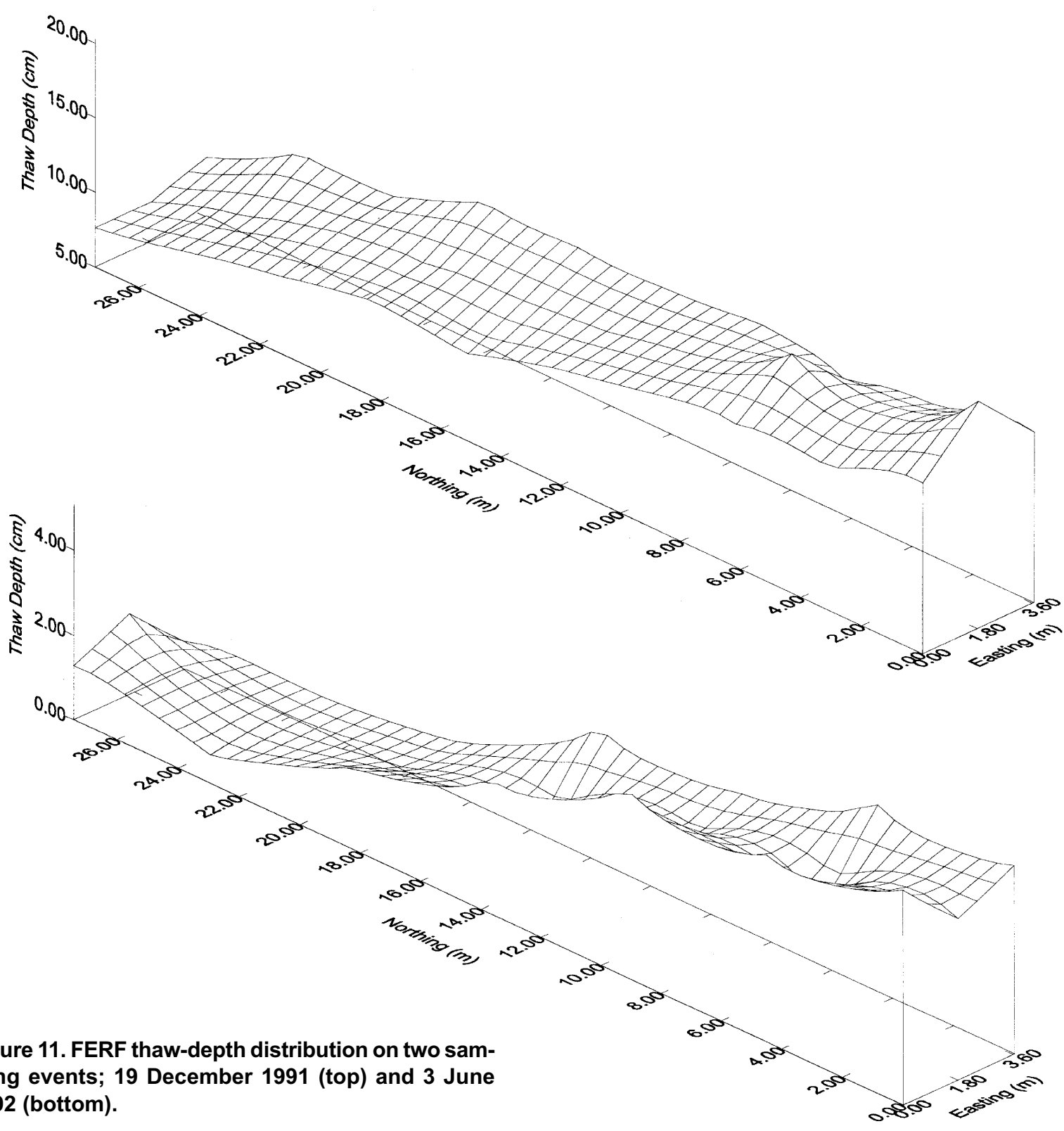



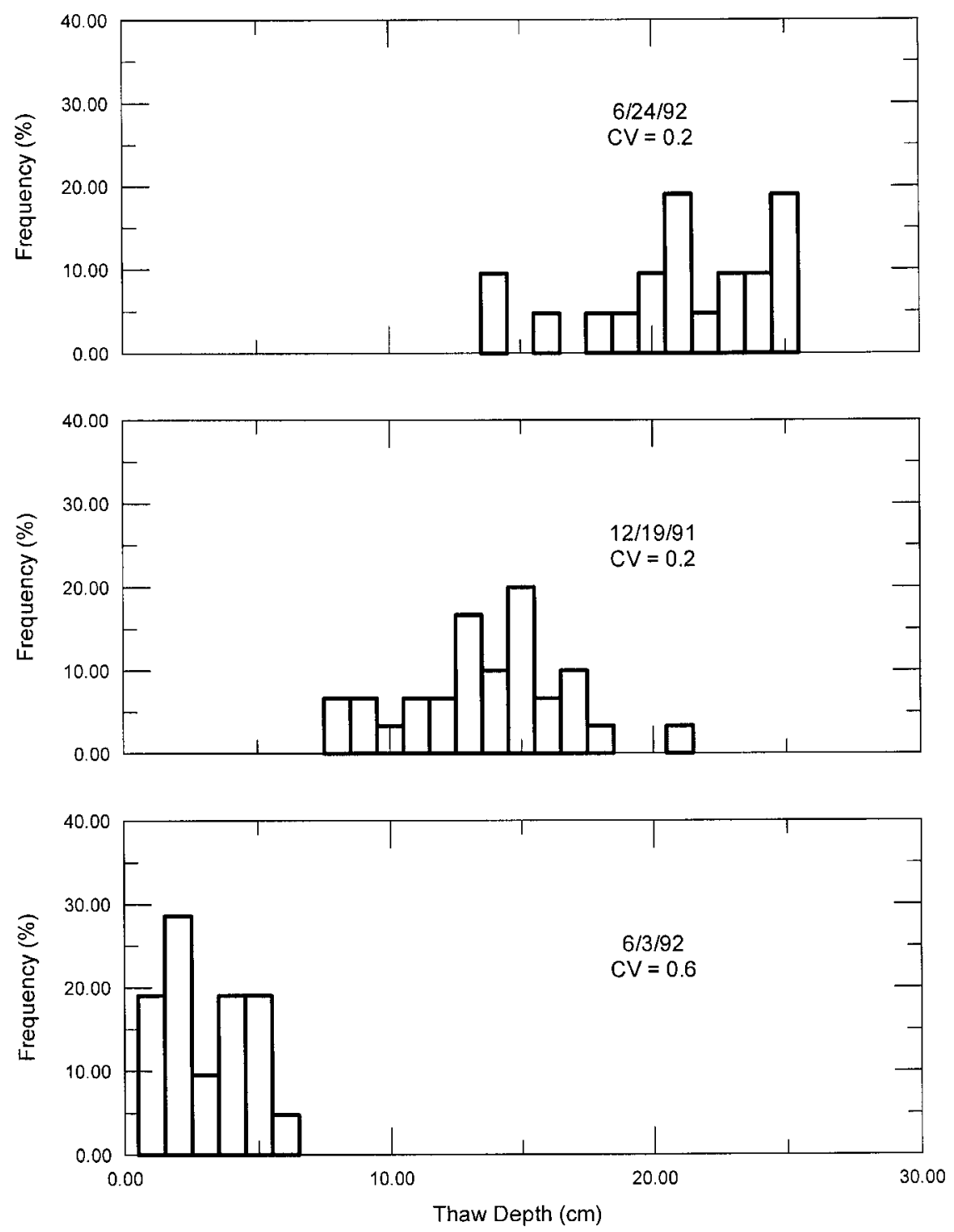

Figure 12. Typical histograms, FERF.

$\mathrm{CV}$ of 0.21 . This value can be considered indicative of a bare (no vegetation), homogenous soil in a temperature-controlled environment, with no solar input. The $\mathrm{CV}$ for Fort McCoy, Wisconsin, was the highest due to trees present along the sides of the trail (which contributed a disparity in shading) and to water ponding and a stream crossing in some parts of the trail. The variation of thaw depth distribution on Swan Lake, Minnesota, data sets is due to the slope and aspect of the site (Sharrat et al. 1999). Atquasuk has a higher CV than the rest of the Alaska sites but the reasons are unclear.

\section{SPATIAL STATISTICS}

Variogram functions to determine the correlation distance for thaw depth were used to analyze the data sets. The variogram function is a mathematical model that expresses the statistical variance as a function of the separation distance. For example, several thaw depth measurements taken at nearly the same point (e.g., point 20) will have nearly the same value, so the variation will be small. If spatial correlation exists, sequentially increasing the separation distance between data points will yield a larger variance in the data. This is the process used to generate a variogram where separation distance is plotted on the $\mathrm{x}$-axis and the variance on the $y$-axis. Eq 2 defines the variogram. If the variance increases with the separation distance, then the thaw depth is correlated with distance. At the point when an increase in separation distance no longer causes a corresponding increase in the variance, the variogram reaches a plateau. The distance corresponding to the start of the plateau is called the range and the variance value at the plateau is called the sill. The vertical jump of variance 


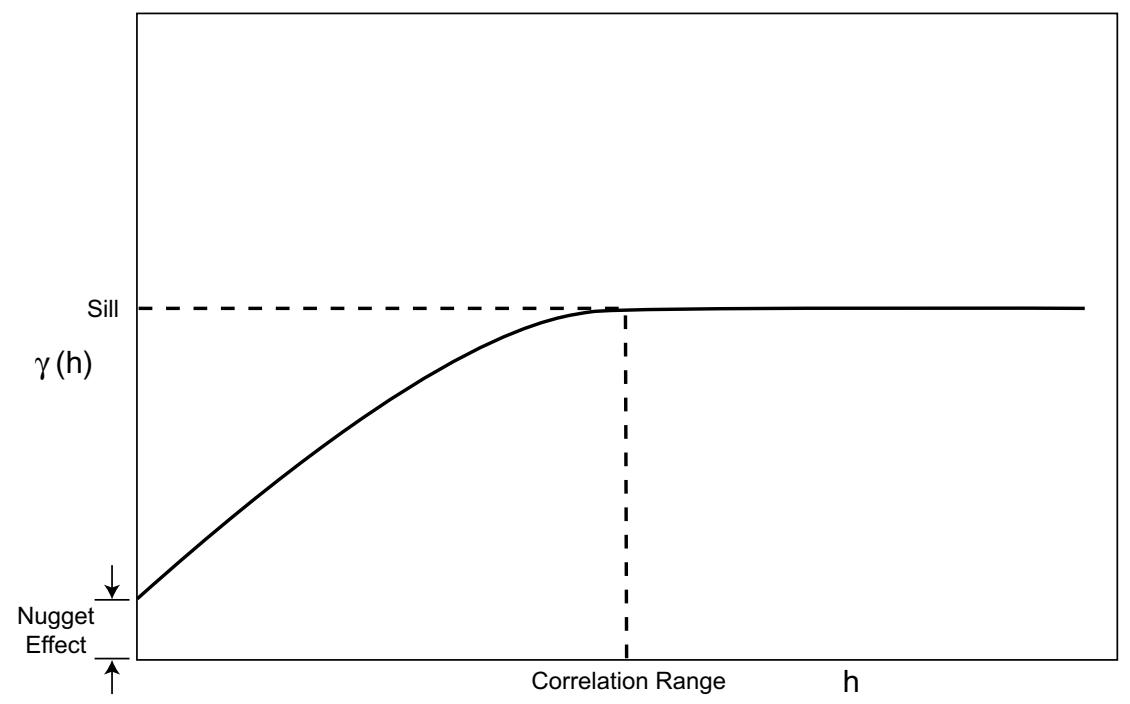

Figure 13. Sample variogram.

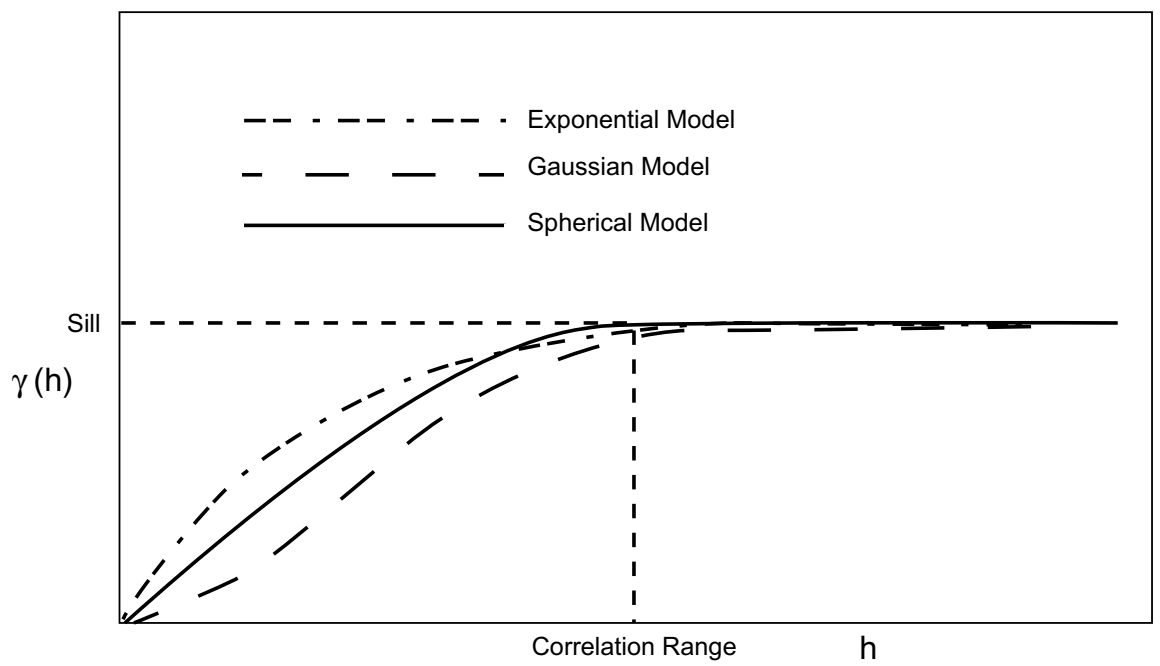

Figure 14. Three most commonly used transition models with the same range and sill (spherical, exponential, and Gaussian).

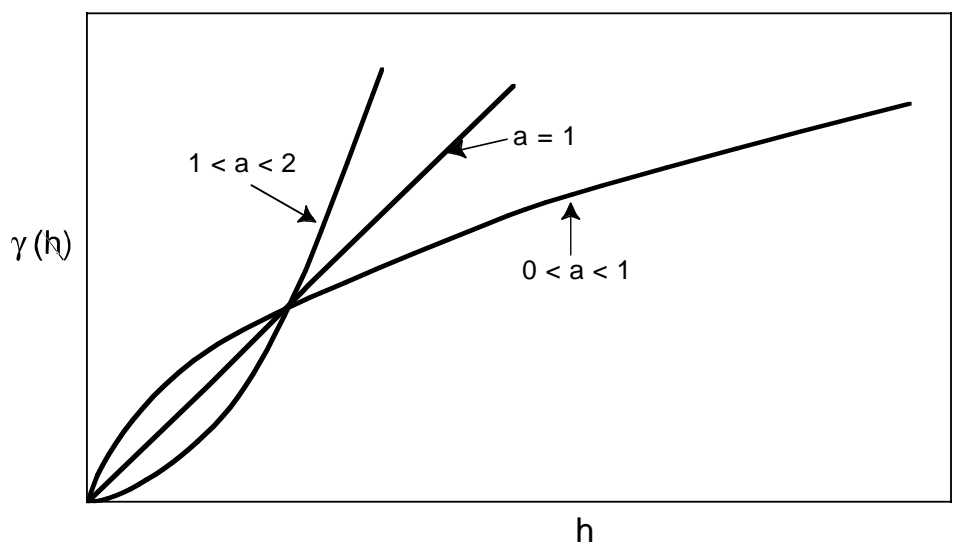

Figure 15. Power model. 
at the origin when separation distance is zero is called the nugget effect. Measurement error and/or natural occurrences can cause this discontinuity at the origin. These values are illustrated in Figure 13.

$$
\gamma(h)=\frac{1}{2 N(h)} \sum_{i=1}^{N(h)}\left[z x_{\mathrm{i}}-z\left(x_{\mathrm{i}}+h\right)\right]^{2}
$$

where $\gamma(h)=$ variance

$h=$ separation distance

$x_{\mathrm{i}}=$ position of one sample in the pair

$x_{\mathrm{i}}+h=$ position of other sample in the pair

$z=$ thaw depth

$N=$ number of pairs of data.

The basic variogram models are divided into two types; those that reach a plateau, which are called transition models, and those that do not. Theoretical models such as spherical, exponential, Gaussian, and power (or linear) models are used to fit the thaw depth on the variogram plot (Fig. 14 and 15). The spherical model is the most commonly used transition model (eq 3 ) and has a linear behavior at small separation distance near the origin but flattens out at larger distance and reaches a sill at $a$. The tangent at the origin reaches the sill at about two-thirds of the correlation range. The exponential model is another commonly used transition model (eq 4). The exponential model rises more steeply near the origin and flattens out more gradually. Like the exponential model, the Gaussian model reaches its sill asymptotically with a parabolic behavior near the origin, and the sill is defined as the "practical range" or the distance at which the variogram value is $95 \%$ of the sill (eq 5). The power or linear model is not a transition model since it does not reach a sill but continuously increases with separation distance $h$ (eq 6). The software we used for variogram analysis is Variowin (Pan-

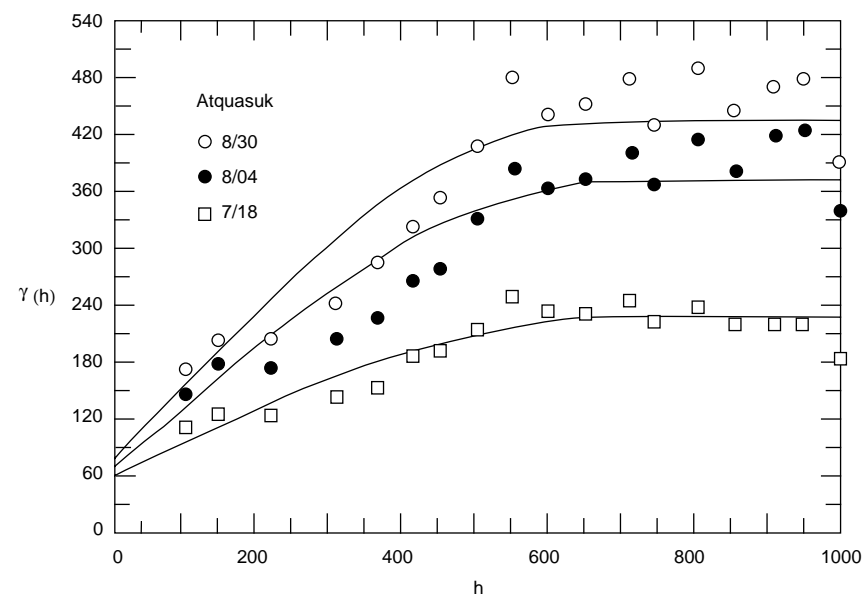

a. Atquasuk. natier 1996). According to ASTM standards, variogram analysis should have at least 20 pairs of data (ASTM D 1996).

Spherical Variogram Model

$$
\gamma(h)=\left\{\begin{array}{l}
1.5 \frac{h}{a}-0.5\left(\frac{h}{a}\right)^{3} \text { if } h \leq a, \text { otherwise } \\
1 .
\end{array}\right.
$$

\section{Exponential Variogram Model}

$$
\gamma(h)=1-\exp \left(-\frac{3 h}{a}\right) .
$$

\section{Gaussian Variogram Model}

$$
\gamma(h)=1-\exp \left(-\frac{3 h^{2}}{a^{2}}\right) .
$$

Power Model

$$
\gamma(h)=|h|^{a} .
$$

\section{Alaska North Slope}

The variogram model that best fit the North Slope thaw depth data was the spherical model. Spatial correlations were found on Atquasuk, Betty Pingo, Happy Valley, and West Dock data sets. These data grids are situated on the coastal plain except for Happy Valley (near the foothills). Atquasuk shows the correlation range of approximately $660 \mathrm{~m}$ and with sill ranging from 230 to 440 depending on the sampling date (Fig. 16a). The correlation range for the three sampling dates is constant. Betty Pingo exhibits a correlation range of up to $450 \mathrm{~m}$ and sill varying from 140 to 370 (Fig. 16c). The thaw depth correlation range for Betty Pingo data

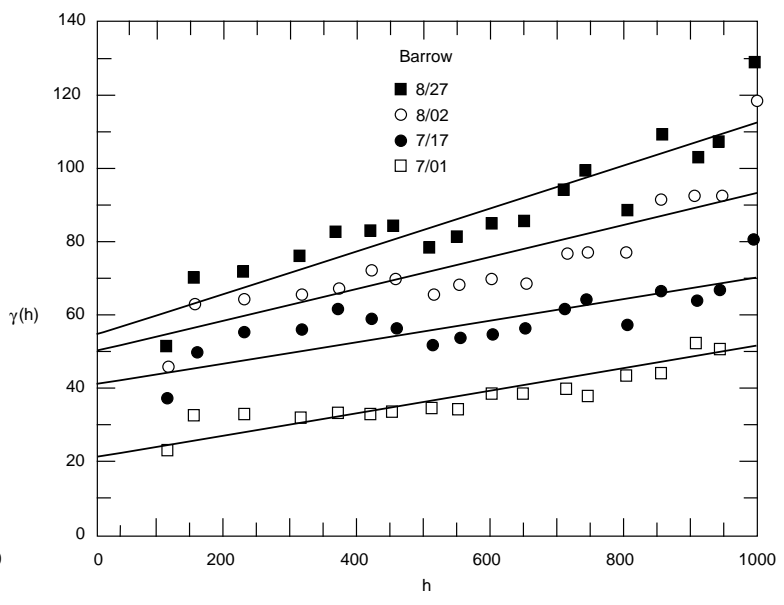

b. Barrow.

Figure 16. Variogram plots for Alaska North Slope. 


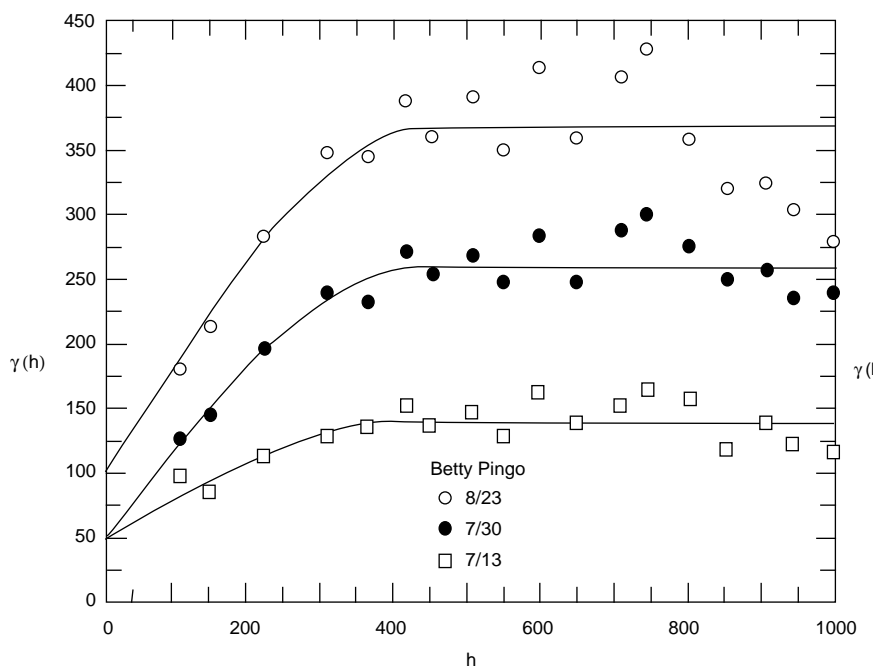

c. Betty Pingo.

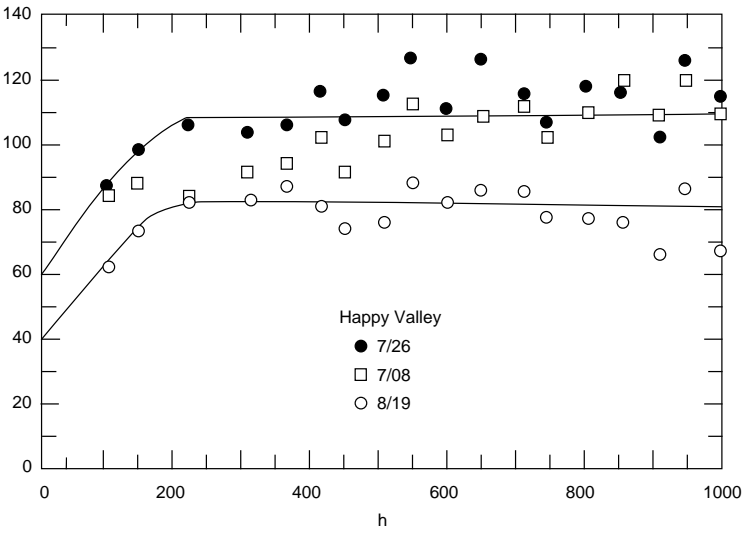

d. Happy Valley.

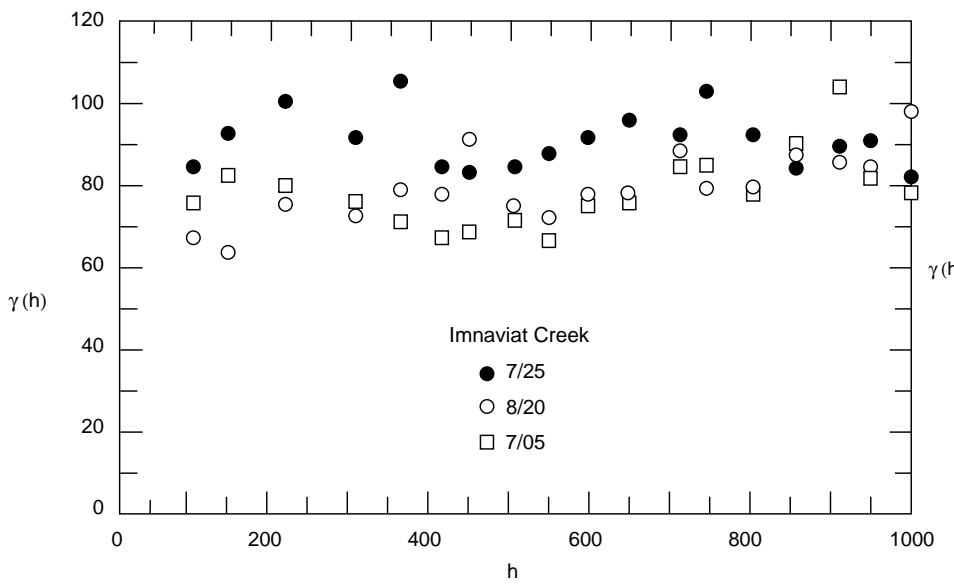

e. Imnaviat Creek.

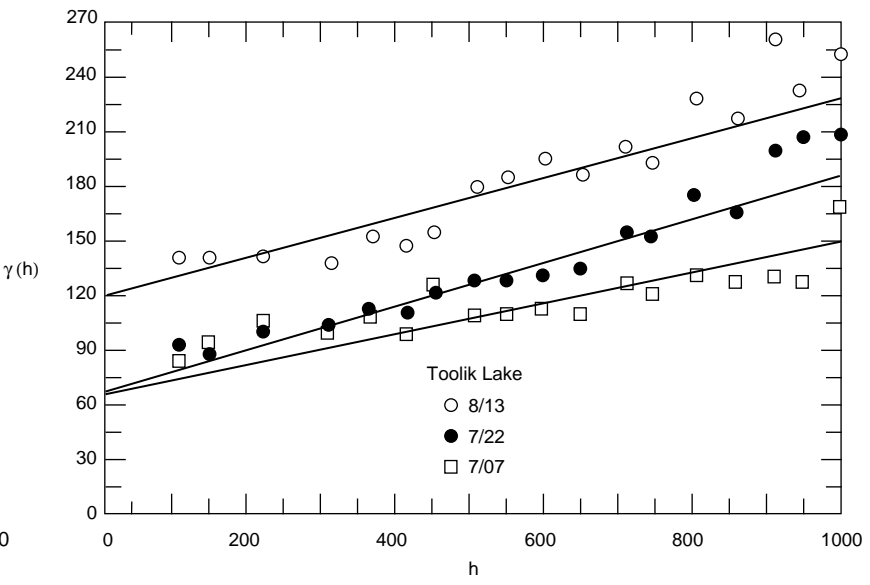

f. Toolik Lake.

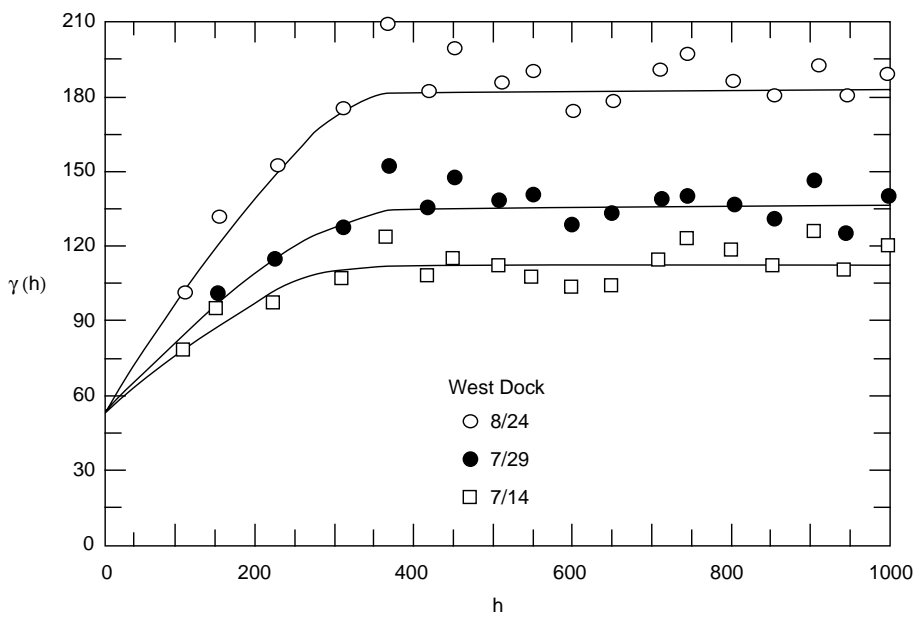

g. West Dock.

Figures 16 (cont'd). Variogram plots for Alaska North Slope. 


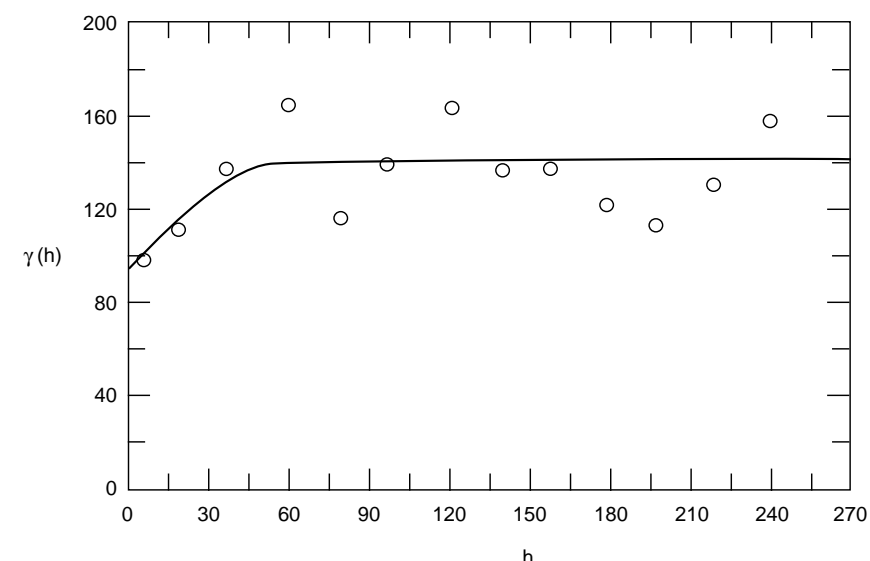

Figure 17. Fort McCoy variogram.

sets increases for the first two sampling dates and remains constant for the third sampling date. The first thaw depth measurements (8 July) on Happy Valley showed no correlation; however, the following two measurements showed a correlation range of 250 and $225 \mathrm{~m}$ with sill of 110 and 82, respectively (Fig. 16d). The sill for West Dock ranged from 110 to 185 with a nearly constant range of $400 \mathrm{~m}$ (Fig. 16g).

The variogram plots for Barrow and Toolik Lake data sets displayed correlation for all data points. The sill and correlation range values were undetermined. Barrow exhibits a linear increase in variance with separation distance (Fig. 16b). For Barrow a much larger sampling area is needed to discern correlation at these separation distances. Toolik Lake variogram also showed a gradual increase in variance starting at 100 $\mathrm{m}$ with a range that cannot be determined (Fig. 16f); the farther apart the points, the greater the variance. Similar to Barrow, a larger sampling area is needed for Toolik Lake to detect the spatial correlation range. Both Toolik Lake and Happy Valley are near each other and situated on the foothills, which have similar vegetation, slopes, and local weather.

Figure 16e shows the Imnaviat Creek variogram where the statistical variance fluctuated throughout the sampling area with no correlation. The total absence of spatial correlation for Imnaviat Creek meant that the separation distance or sampling interval of $100 \mathrm{~m}$ is so far apart that one sampling location is unrelated to the next at these sites. It also could be due to the terrain slope, vegetation, or local weather.

\section{Fort McCoy, Wisconsin}

The thaw depths that were measured at Fort McCoy had a correlation range of $61 \mathrm{~m}$ and a maximum statistical variance (sill) of 22 (Fig. 17). The spherical variogram model is the best fit for these data. This result is consistent with a similar analysis by Kestler (1996).

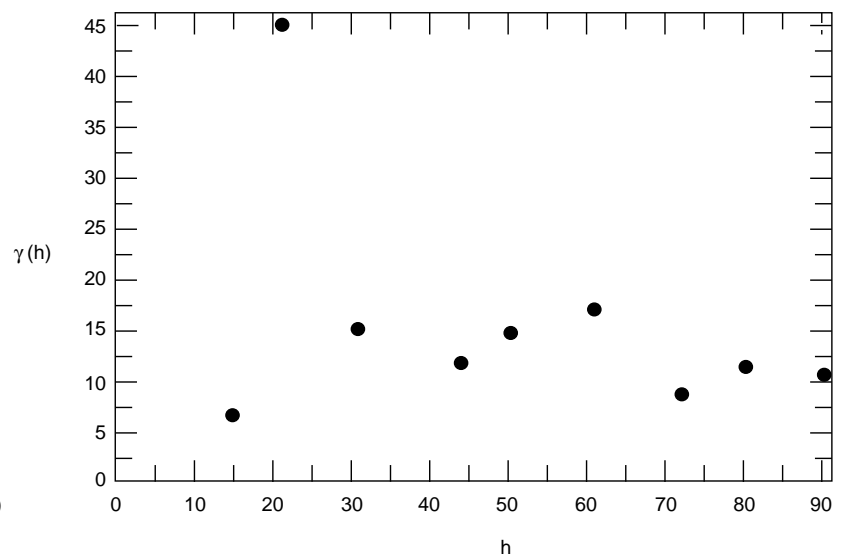

Figure 18. Swan Lake variogram.

\section{Swan Lake, Minnesota}

The variogram plots for Swan Lake did not reveal any spatial correlation. Figure 18 shows a typical variogram plot with scattered points. The layout (Fig. 5) with a sampling distance of $15 \mathrm{~m}$ is too far apart, so that correlation distance was undetectable. Perhaps a shorter sampling distance or a regular sampling grid is needed to determine the correlation. All the variogram plots for Swan Lake data sets are shown in Appendix B1. Solar radiation accounted for $11 \%$ of the variability in thaw depth across the depression, with more rapid thaw occurring at locations with greater radiation because of the geometry of the terrain (slope and aspect). Most of the lower elevation thawed faster than the higher areas (Sharratt et al. 1999).

\section{FERF}

Best fits were obtained using exponential, power, and linear variogram models for FERF data sets. The typical results from variogram analysis are shown in Figure 19a and b. Plots for all the data sets are located in Appendix B2. All plots showed that the thaw-depth measurements have an increase in variance with separation distance; however, the correlation range cannot be determined. Because the distribution of the thaw depth gradually slopes across the test section as shown in Figure 11, the variogram plots tend to have a concave correlation.* The data sets with the largest number of sampling points most strongly show this concave behavior. The absence of the sill indicates that the correlation range was larger than the maximum spatial distance of $27 \mathrm{~m}$ and a larger sampling area is needed to determine the correlation distance.

* Personal communication, Dr. Matthew Sturm, CRREL, Fairbanks, Alaska, 2000. 


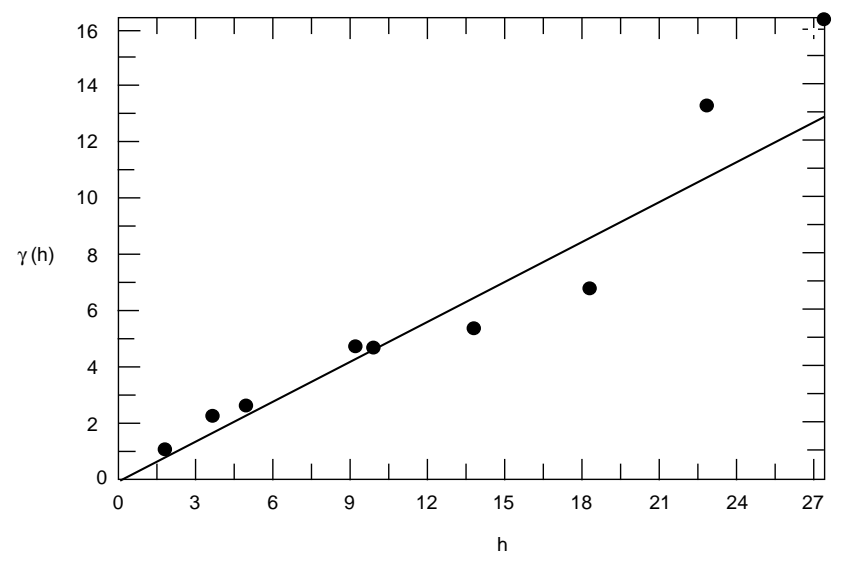

a. 21 June 1992.

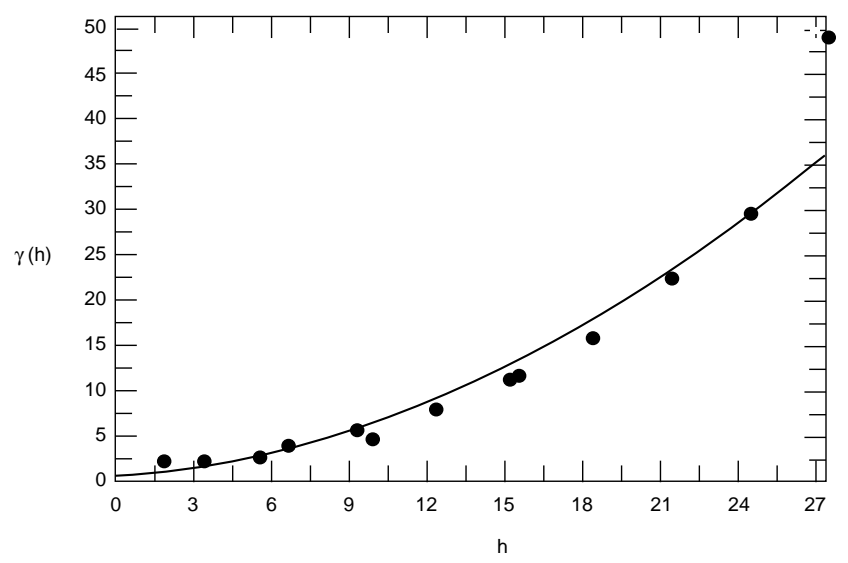

b. 19 December 1991.

Figure 19. Typical variogram plots of FERF data sets.

\section{APPLICATIONS}

Variogram analysis allows one to quantify the spatial variability of the thaw depth for various types of terrain. Standard statistics (i.e., standard deviation, histogram) do not relate to the relative positions of the test data but are essential information on the variation of thaw depth. The correlation range and variation of thaw depth over a terrain can be used to quantify the thaw depth variability in models where thaw depth is needed, such as mobility performance models.

The depth of thaw causes a significant impact on vehicle mobility (Shoop 1990). Soils with a thawed layer can be saturated due to snowmelt, rain, and water drawn to the soil during the freezing process. The underlying frozen layer traps this moisture, so the upper soil layer is wet and weak. A thaw-depth algorithm has been incorporated into a vehicle performance model called NATO Reference Mobility Model II (NRMMII) (Richmond et al. 1995). NRMMII predicts maximum attainable speed of a vehicle operating on a terrain (Ahlvin and Haley 1992). The terrain is divided into a terrain unit for corresponding soil type, soil strength, soil wetness index, soil strength, obstacles, and surface roughness. Thaw depth is an input variable to a terrain or scenario file for NRMMII and is assumed uniform throughout the terrain or can be specified for each terrain unit.

Kestler (1996) used statistical, geostatical (variogram), and regression analyses to establish whether variation in subgrade reflects the performance of a test section. Her study concluded that thaw depth, water content, percentage of water standing, and soil strength influenced the test section performance. Also, Kestler et al. (1994) identified spatial correlation as a function of distance using the falling weight deflectometer (FWD) data to assess the overall pavement structure. The FWD is towed by a vehicle and is used to deter- mine pavement stiffness and deflection. Using the knowledge of the lengths over which any particular indicator value is correlated can translate into substantial savings by optimizing pavement evaluation tests.

Temporal and spatial variability on soil strength has been investigated for off-road mobility to define the soil strength uncertainties, and for forecasting soil strength (Mason et al. 1997). Mason et al. used soil strength data to develop coefficients to forecast the changes of soil strength with time, and spatial relationship on soil strength with the terrain elevation using variogram and kriging methods.

\section{DISCUSSION}

The average thaw depth versus the standard deviation of all the data sets from all sites is shown in Figure 20. The variance in the thaw is proportional to the thaw depth according to eq 7 and 8 .

$$
\begin{aligned}
& \sigma_{\text {thaw }}=0.3007 m_{\text {thaw }} \\
& \sigma_{\text {thaw }}=0.1513 m_{\text {thaw }}
\end{aligned}
$$

where $\sigma_{\text {thaw }}$ is the standard deviation of the thaw depth and $m_{\text {thaw }}$ is the average thaw depth $(\mathrm{cm})$. The controlled test section in the FERF has a slightly smaller slope.

At sites where data was collected with thaw progression (i.e., Alaska), spatial correlation ranges are fairly constant as the thaw depth progresses. In Swan Lake, Minnesota, data was collected with time but no correlation range was found as discussed previously.

The data sets were collected at various sampling scales. For example, at Swan Lake, the data were measured within the confines of the shallow depression, and in the case of the FERF, it is the dimension of the 


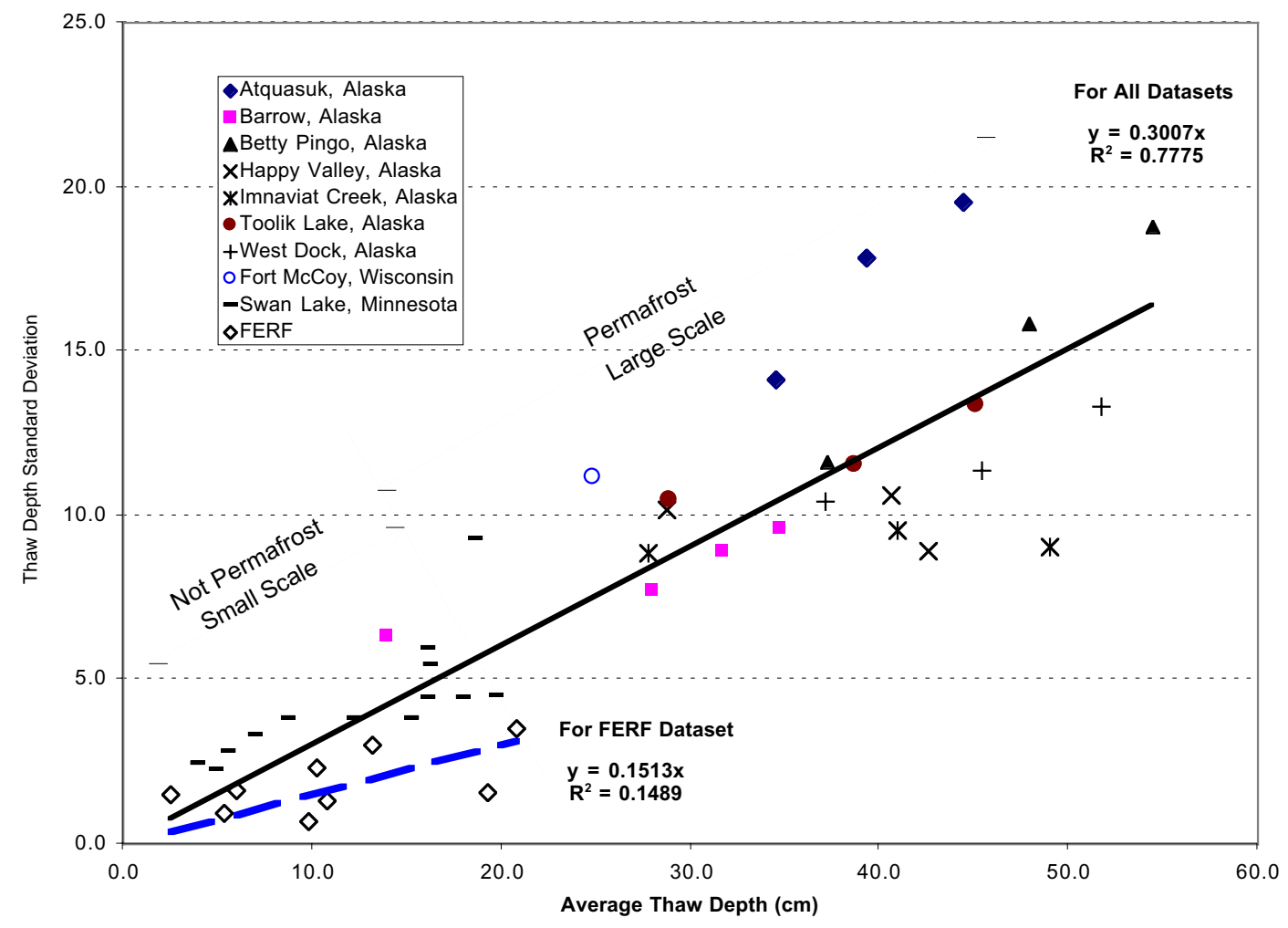

Figure 20. Variability with thaw depth.

installation. These limit the spatial variability analysis to determine the correlation range on these sites, and are apparent in the variograms.

Solar radiation is one of the influence factors for slopes with varying orientation and gradient. Thus, the change in solar radiation accounts for some of the variability in the Alaska sites on the foothills (Nelson et al. 1997), and in the Swan Lake, Minnesota, site (Sharrat et al. 1999).

The correlation range on Table 2 can be used as an initial approximation for the specific terrain. For example, in the case for seasonal thaw depth without permafrost, the correlation range can be estimated at about $61 \mathrm{~m}$.

These results can be used for analysis of the impact of thaw distribution on predictive models, such as for predicting vehicle mobility. Future research should include evaluation of impact of climate, vegetation, surface roughness, solar radiation, and slope on thaw variability, and how they change with time.

\section{SUMMARY}

Statistical and spatial analyses were performed on existing thaw depth data sets from a variety of climatic and terrain conditions to determine the variability of thaw. These data include permafrost sites in Alaska, temperate sites in the continental United States, including sites in Minnesota and Wisconsin, and a large-scale, controlled test section with no solar input in the Frost Effects Research Facility (FERF) at the Cold Regions Research and Engineering Laboratory (CRREL) in Hanover, New Hampshire.

Variation in elevation, slope, aspect, vegetation, and solar radiation contribute to the variation in thaw. Coefficients of variation ranged from very low values of 0.1 at the controlled site (FERF) to 0.5 and 0.6 at sites with non-uniform elevation, slope/aspect, vegetation, or surface water. Spatial statistic analysis of the thaw depth data show that the correlation range at each site stays constant as thaw progresses. The correlation range at each site can be used as a first approximation for estimating correlation of similar sites. The terrain and surface energy factors were not specifically addressed, making broad generalization regarding the impacts of specific factors difficult.

Even with the wide differences among sites, the standard deviation tends to increase smoothly with thaw depth. A compilation of all data (Fig. 20) shows an increase according to

$$
\sigma_{\text {thaw }}=0.03007 m_{\text {thaw }} \text {. }
$$

Most data fit this trend with the controlled site having a slightly smaller slope. Because the Alaska sites were underlain by permafrost, most of the deepest thaw depths were collected in this environment. 
Results can be used to spatially distribute soil properties based on point data or one-dimensional models, or to populate sparse data sets with terrain properties. They are also useful for analysis of impact of thaw distribution on predictive models, such as for predicting vehicle mobility.

\section{LITERATURE CITED}

Ahlvin, R.B., and P.W. Haley (1992) NATO Reference Mobility Model, Edition II, NRMMII user's guide. U.S. Army Waterways Experiment Station, Geotechnical Laboratory, Technical Report GL-92-19.

ASTM D 5922-96 (1996) Standard guide for analysis of spatial variation in geostatistical site investigations. Annual Book of ASTM Standards, ASTM, West Conshohocken, Pennsylvania, p. 827-830.

Brown, J., P.C. Miller, L.L. Tieszen, and F.L. Bunnell (1980) An Arctic Ecosystem: The Coastal Tundra at Barrow, Alaska. Stroudsburg, Pennsylvania: Dowden, Hutchinson \& Ross, Inc.

Everett, K.R. (1980) Distribution and variability of soils near Atquasuk, Alaska. Arctic and Alpine Research, 12(4): 433-446.

Hinzman, L.D., D.L. Kane, R.E. Gieck, and K.R. Everett (1991) Hydrologic and thermal properties of the active layer in the Alaskan Arctic. Cold Regions Science and Technology, 19: 95-110.

Hinzman, L.D., D.J Goering, and D.L. Kane (1998) A distributed thermal model for calculating soil temperature profiles and depth of thaw in permafrost regions. Journal of Geophysical Research (Atmospheres), 103(22): 28,975-28,991.

Isaaks, E.H., and R.M. Srivastava (1989) An Introduction to Applied Geostatistics. Oxford and New York: Oxford University Press.

Kane, D.L., L.D. Hinzman, Haofang Yu, and D.J. Goering (1994) The use of SAR satellite imagery to measure active layer moisture contents in Arctic Alaska. Presented at the 10th Northern Research Basin Symposium, September 1994.

Kestler, M.A. (1996) Assessing the significance of subgrade variability on test section performance. In Proceedings, Uncertainty in the Geologic Environment: From Theory to Practice, New York, 31 July-3 August. American Society of Civil Engineers, Geotechnical Special Publication, no. 58, vol. 1, p. 685-694.

Kestler, M.A., M.E. Harr, R.L. Berg, and D.M. Johnson (1994) Spatial variability of falling weight deflectometer data: A geostatistical analysis. In Pro- ceedings, 4th International Conference on the Bearing Capacity of Roads and Airfields, vol. 1, p. 317-330.

Kestler, M., S.A. Shoop, K.S. Henry, J.A. Stark, and R.T. Affleck (1999) Rapid stabilization of thawing soils for enhanced vehicle mobility: A field demonstration project. U.S. Army Cold Regions Research and Engineering Laboratory, CRREL Report 99-3.

Komarkova V., and P.J. Webber (1980) Two low Arctic vegetation maps near Atquasuk, Alaska. Arctic and Alpine Research, 12(4): 447-472.

Mason, G.L., T.J. Hurley, and D.A. Grivas (1997) Modeling spatial and temporal variations in soil strength: A vehicle mobility application. Transportation Research Board, 12-16 January 1997, Paper No. 971178.

Nelson, F.E., N.I. Shiklomanov, G.R. Mueller, K.M. Hinkel, D.A. Walker, and J.G. Bockheim (1997) Estimating active-layer thickness over a large region: Kuparuk River Basin, Alaska, U.S.A. Arctic and Alpine Research, 29(4): 367-378.

Pannatier, Y. (1996) Variowin Version 2.2, Software for Spatial Data Analysis in 2D. New York: SpringerVerlag.

Ping, C.L., G.J. Michaelson, Y. Shur, and W.M. Loya (1994) The genesis, classification, and management of permafrost soils. Alaska soil geography field trip. University of Alaska Fairbanks, 18-30 June 1994.

Richmond, P.W., S.A. Shoop, and G.L. Blaisdell (1995) Cold regions mobility models. U.S. Army Cold Regions Research and Engineering Laboratory, CRREL Report 95-1.

Sharratt, B.S., G.R. Benoit, J.A. Daniel, and J.A. Staricka (1999) Snow cover, frost depth, and soil water across a prairie pothole landscape. Soil Science, 164(7): 483-492.

Shoop, S.A. (1990) Mechanisms controlling vehicle mobility on a thawing soil. In Proceedings, 10th International Conference of the ISTVS, Kobe, Japan, 20-24 August, 301-311.

Shoop, S.A., R.T. Affleck, and P.W. Richmond (2000) Vehicle mobility on thawing silt. U.S. Army Cold Regions Research and Engineering Laboratory, unpublished internal report.

Walker, D.A. (1998) GIS Data from the Alaska North Slope. INSTAAR, University of Colorado (http:// arcss.colorado.edu/Catalog/arcss017.html).

Walker, D.A., K.R. Everett, P.J. Webber, and J. Brown (1980) Geobotanical Atlas of the Prudhoe Bay Region, Alaska. U.S. Army Cold Regions Research and Engineering Laboratory. 


\section{APPENDIX A: THAW-DEPTH HISTOGRAMS}
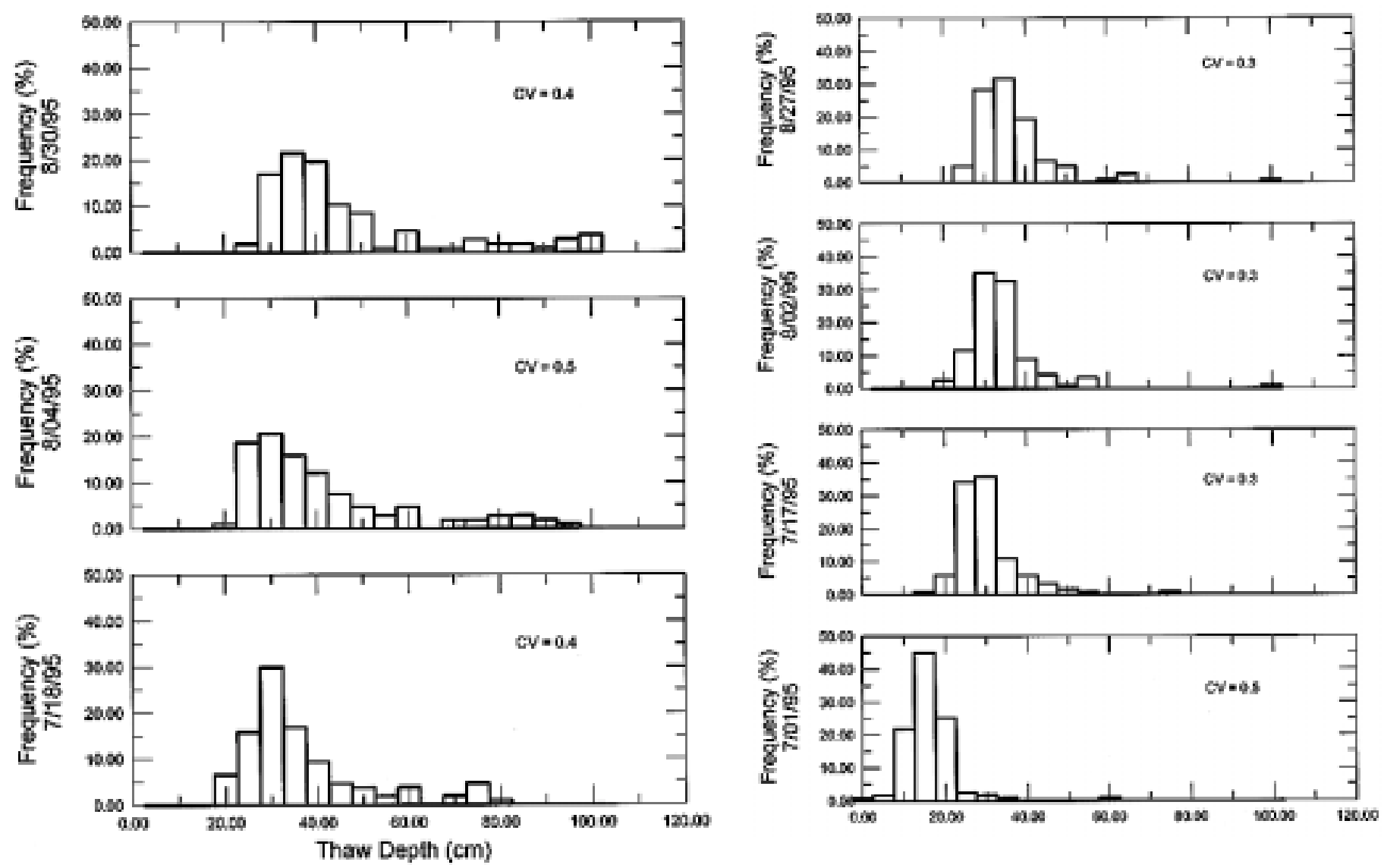

Figure A1. Atquasuk, Alaska.

Figure A2. Barrow, Alaska. 

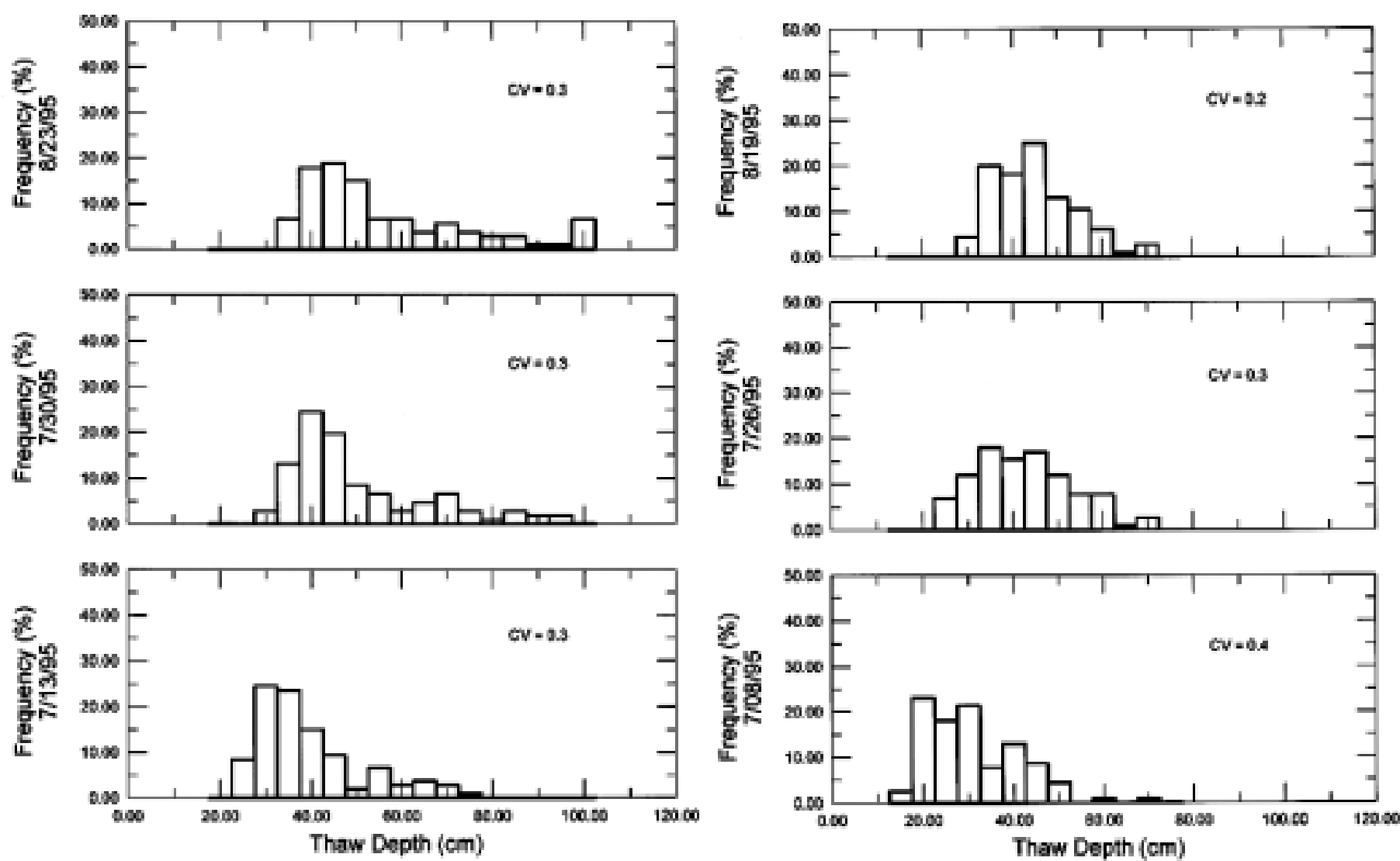

Figure A3. Betty Pingo, Alaska.
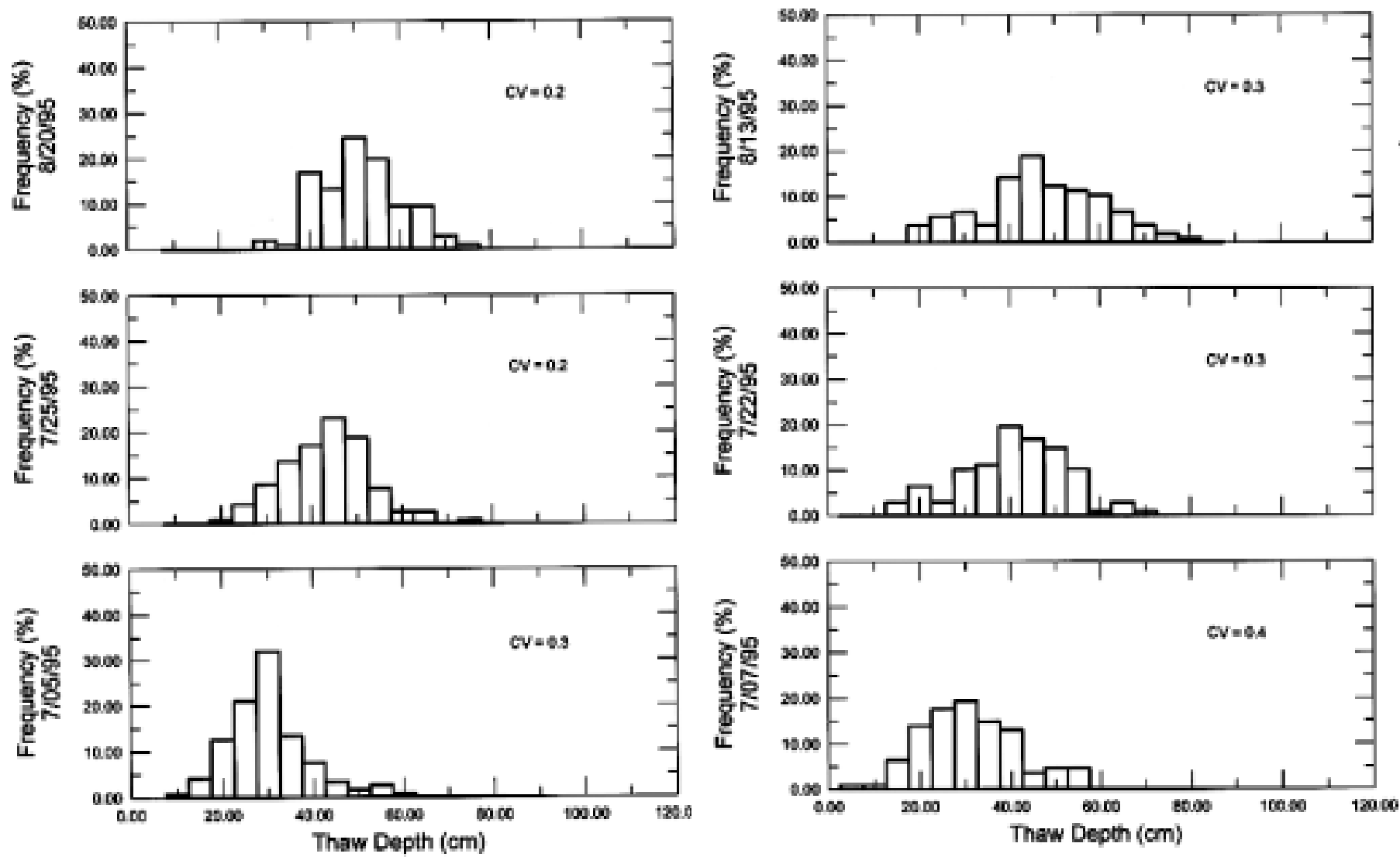

Figure A5. Imnaviat Creek, Alaska.

Figure A6. Toolik Lake, Alaska. 

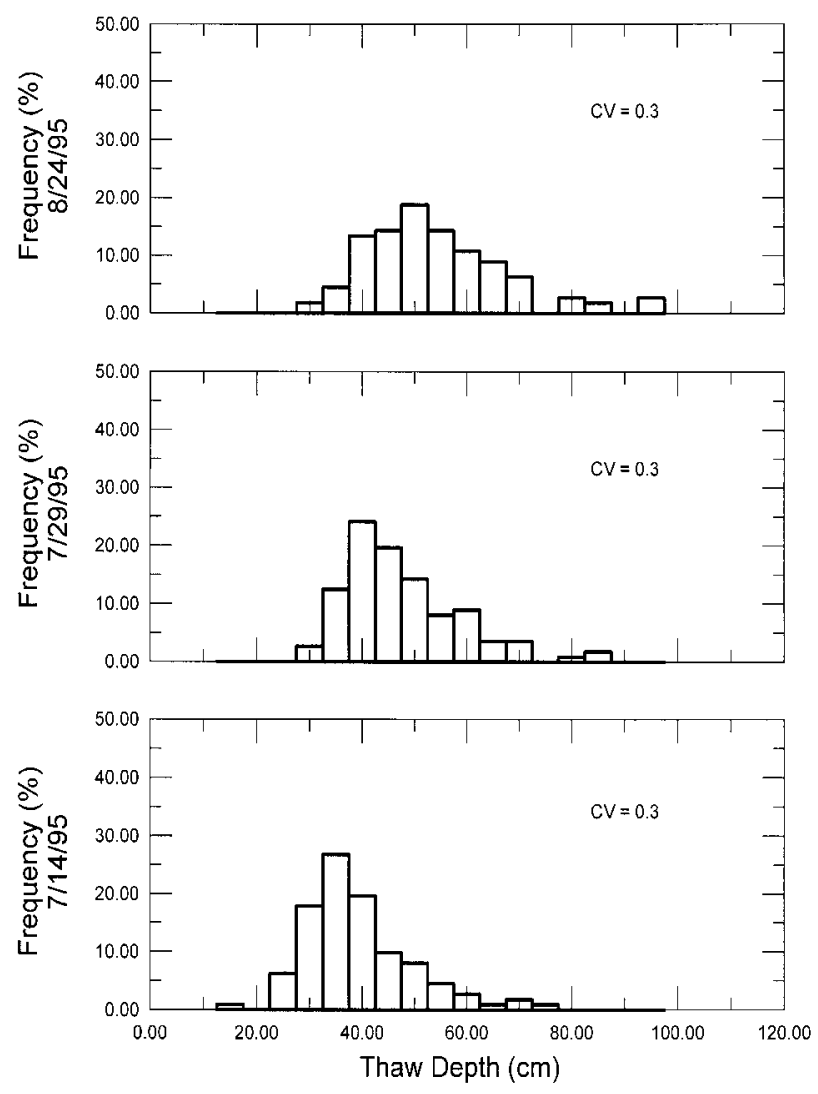

Figure A7. West Dock, Alaska. 

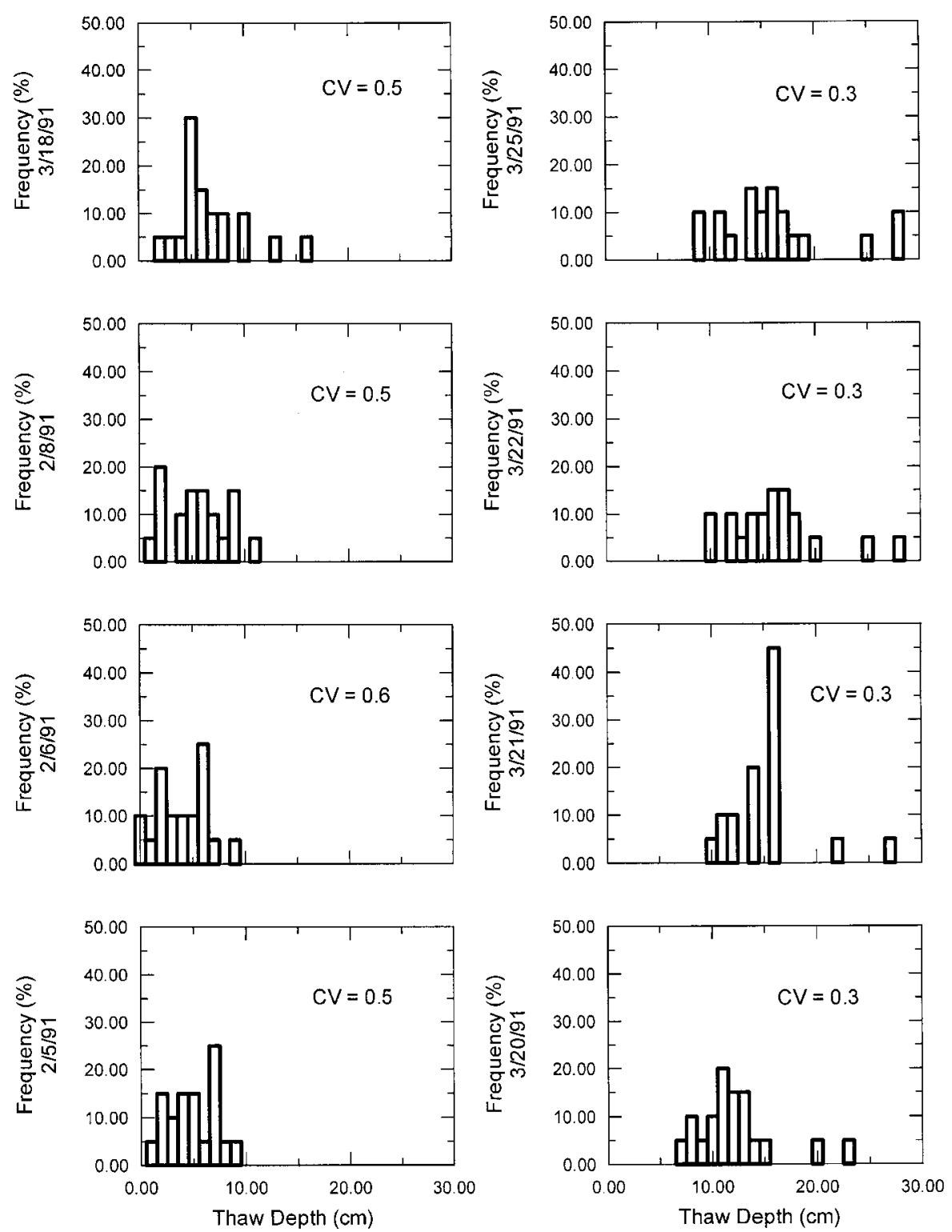

Figure A8. Swan Lake, Minnesota. 

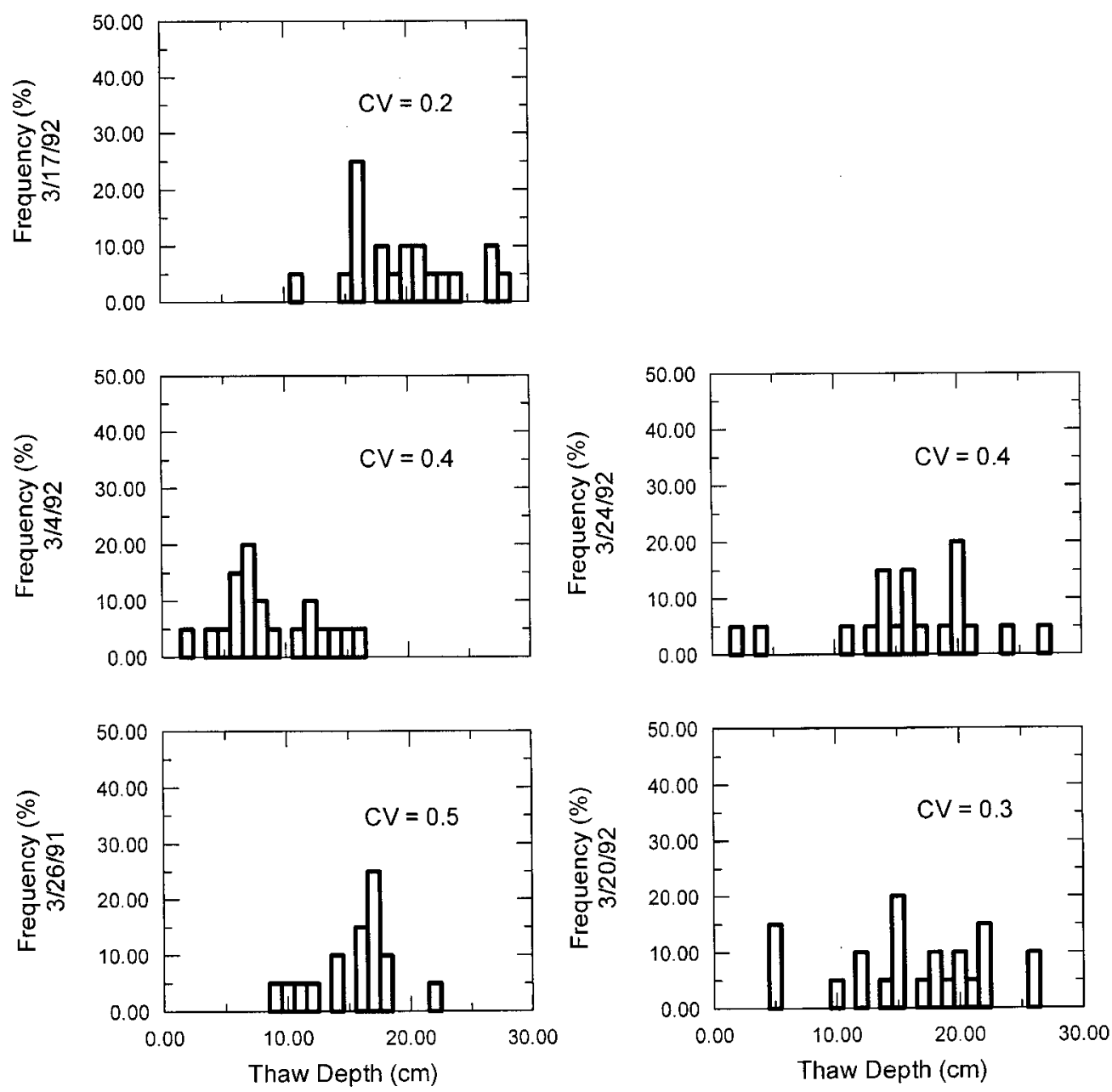

Figure A8 (cont'd). 

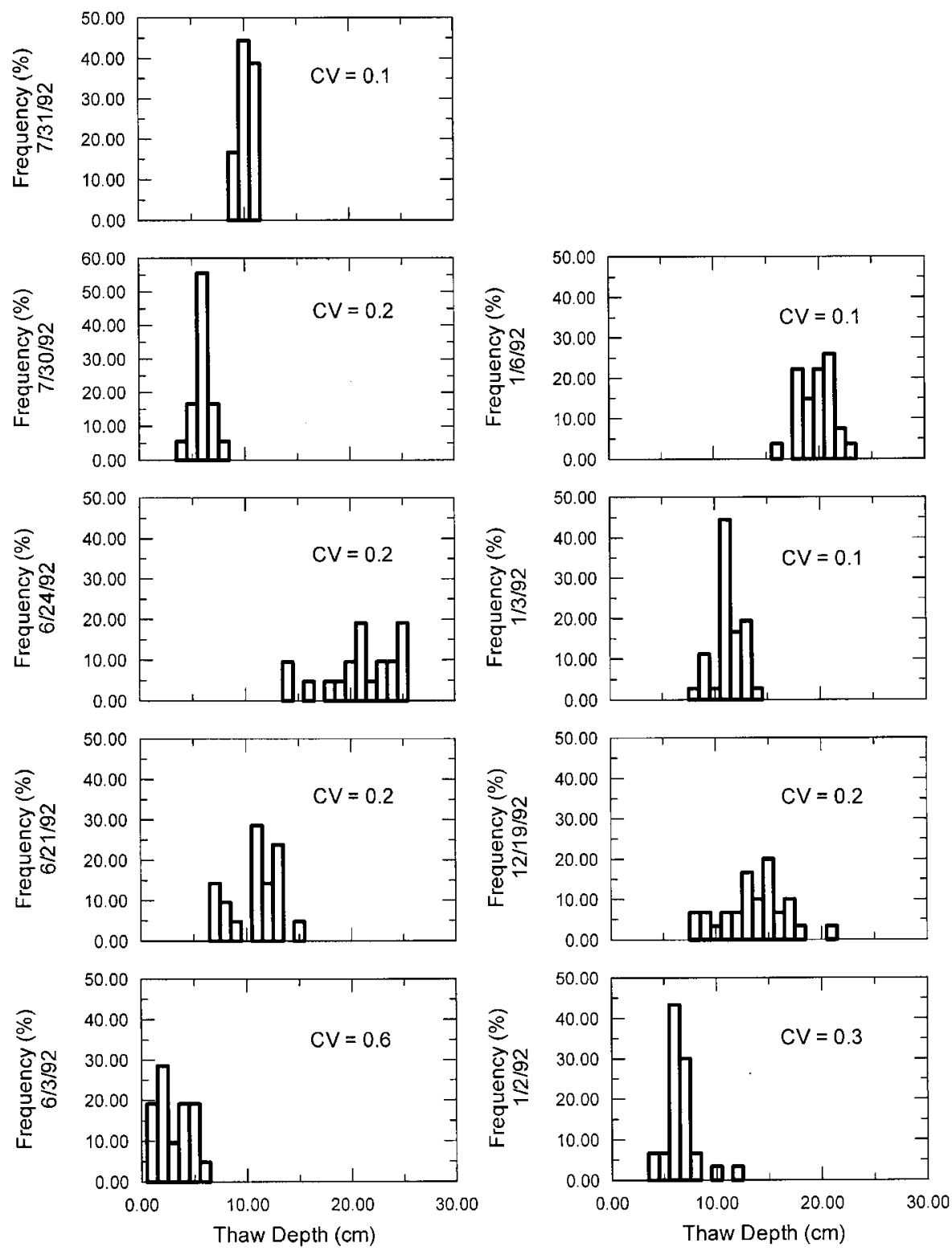

Figure A9. FERF 
APPENDIX B1. SWAN LAKE THAW-DEPTH VARIOGRAMS

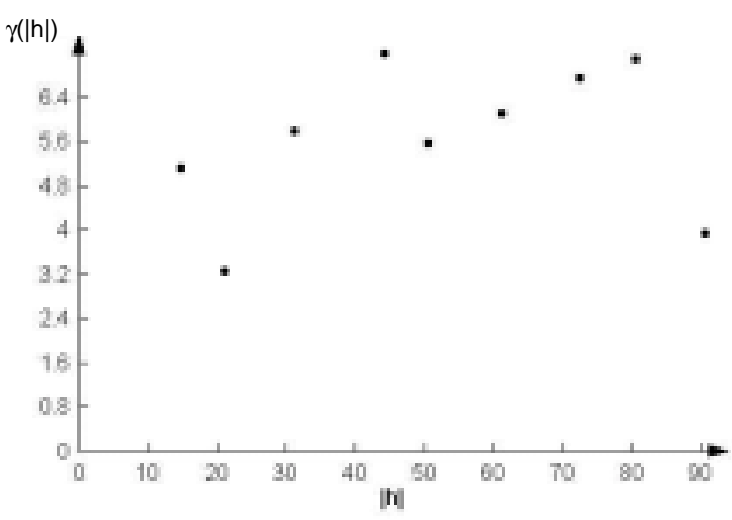

5 Feb 91

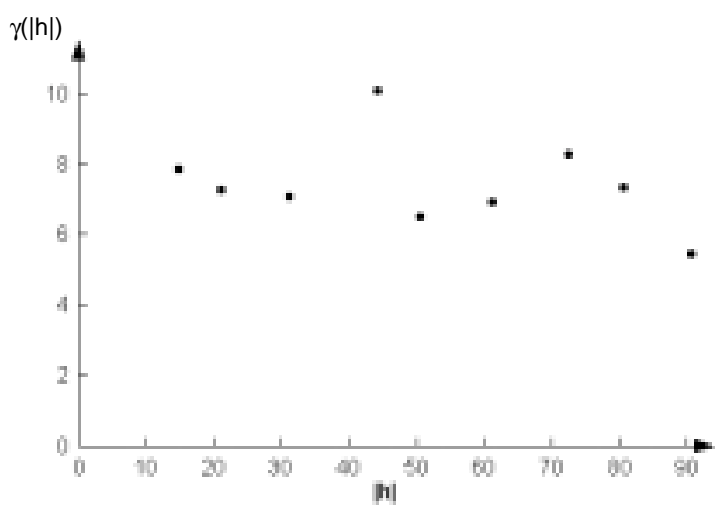

8 Feb 91

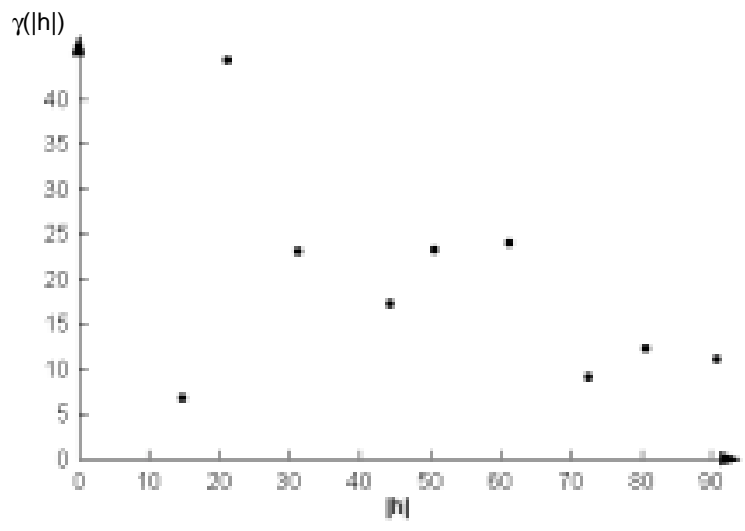

20 Mar 91

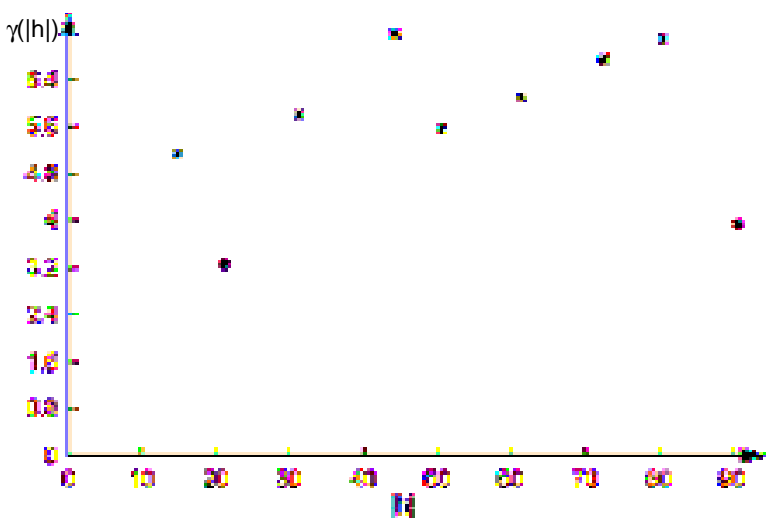

6 Feb 91

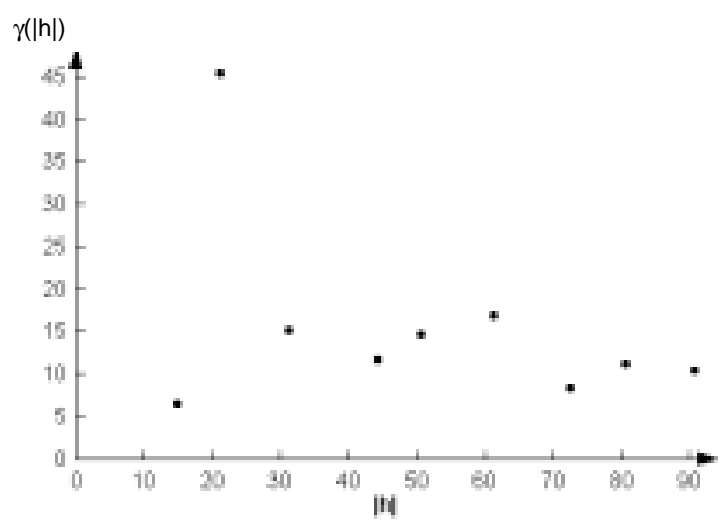

18 Mar 91

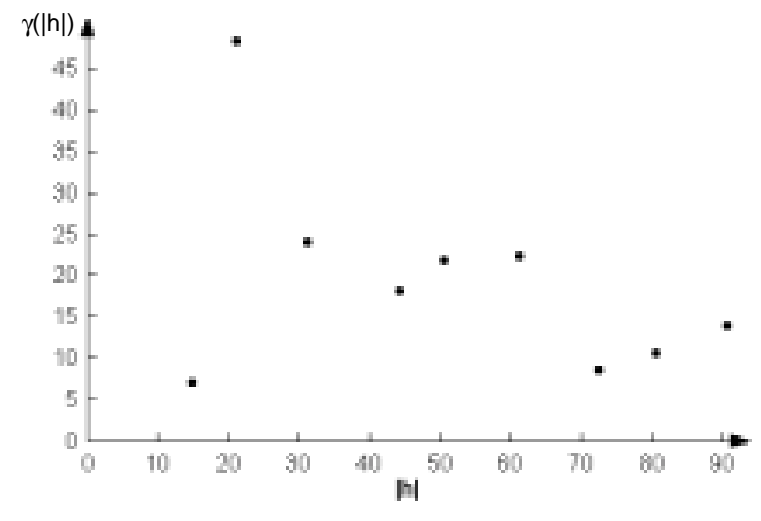

21 Mar 91 


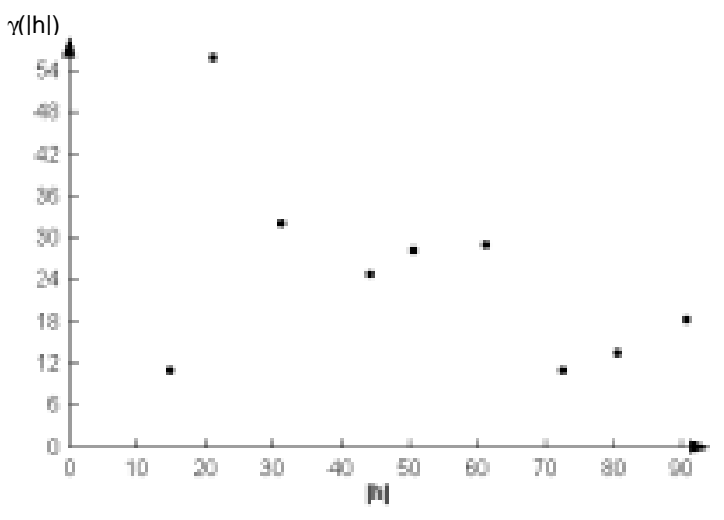

22 Mar 91

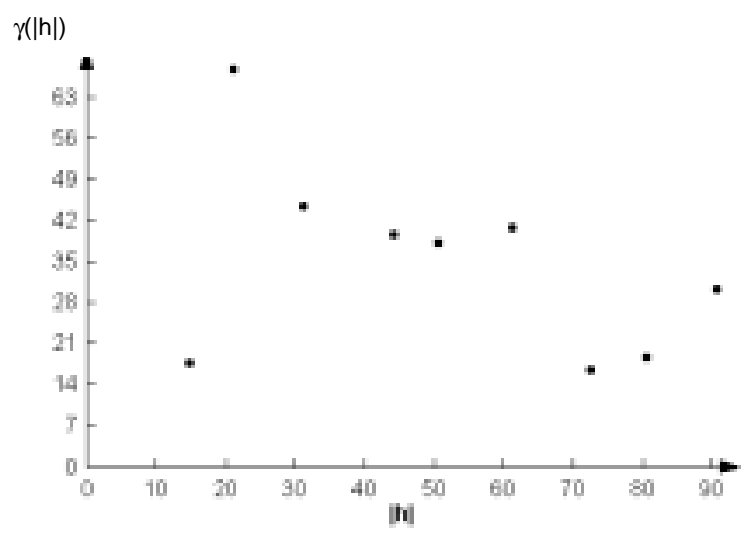

25 Mar 91

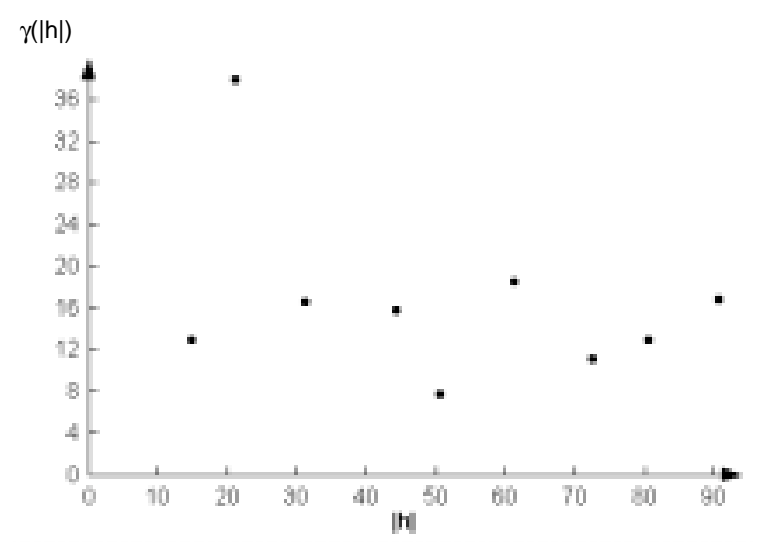

4 Mar 92

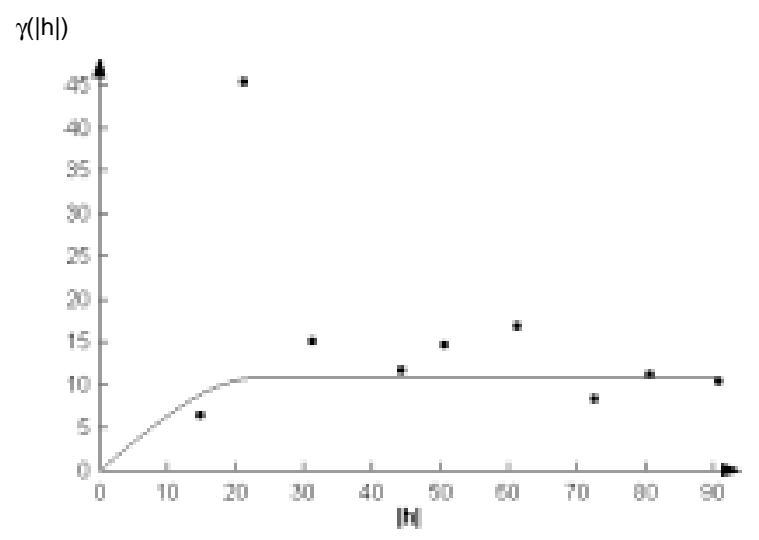

18 Mar 91

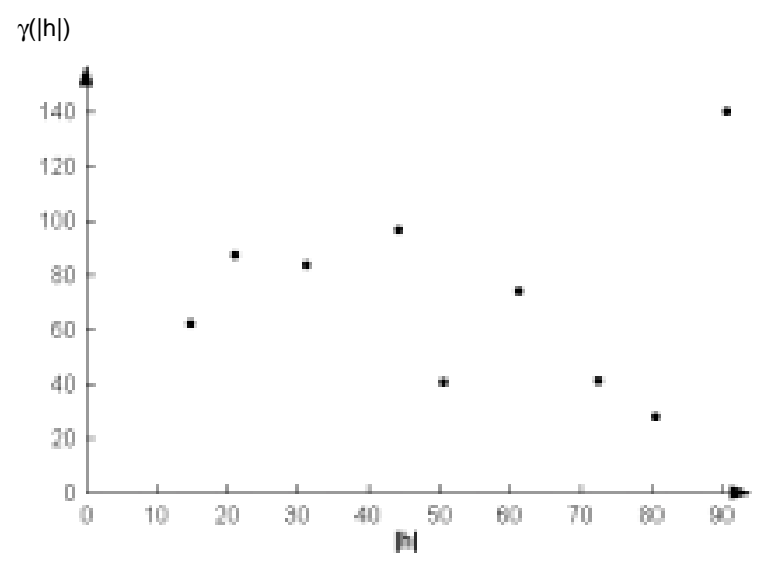

26 Mar 91

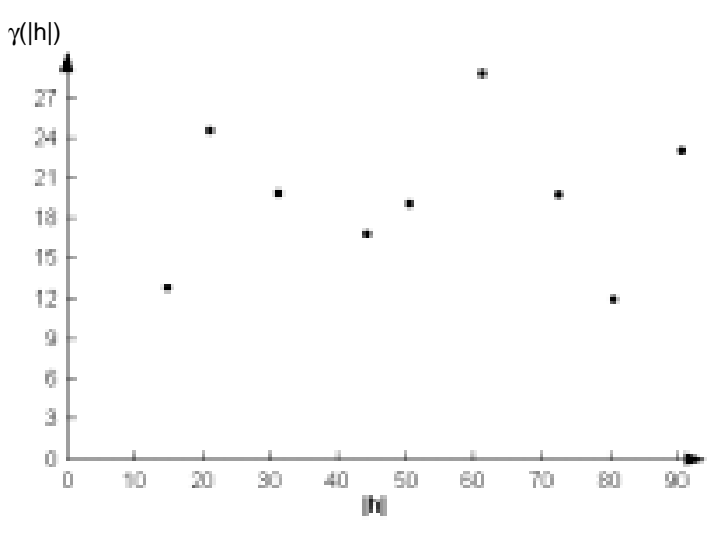

17 Mar 92 


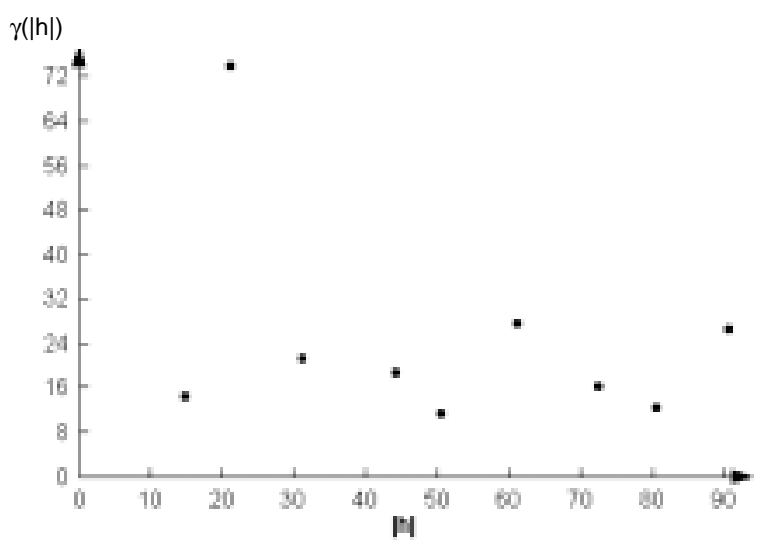

20 Mar 92

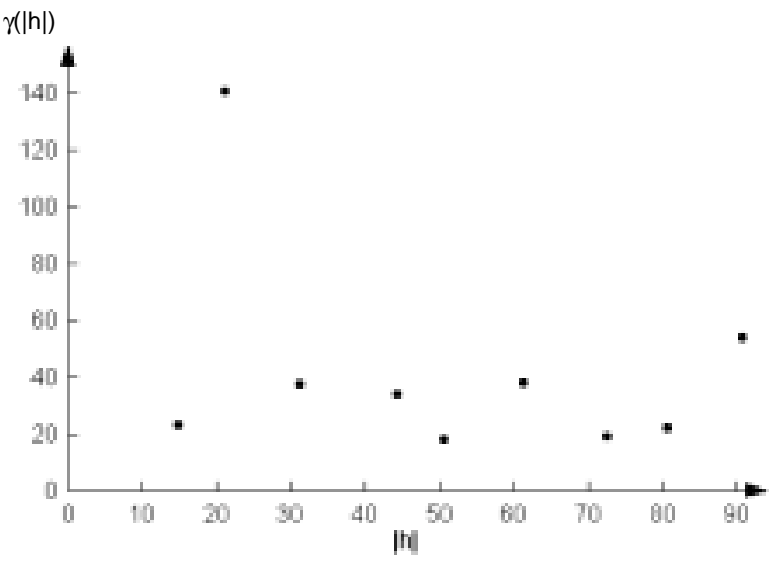

24 Mar 92 


\section{APPENDIX B2: FERF THAW-DEPTH VARIOGRAMS}

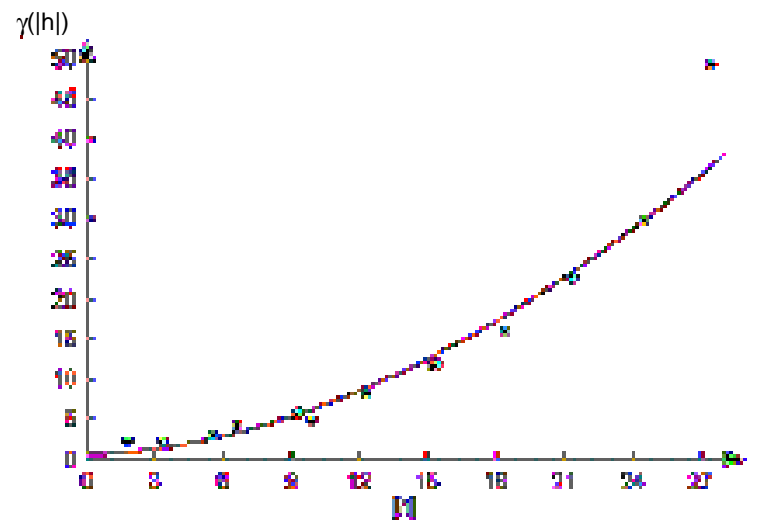

19 Dec 91

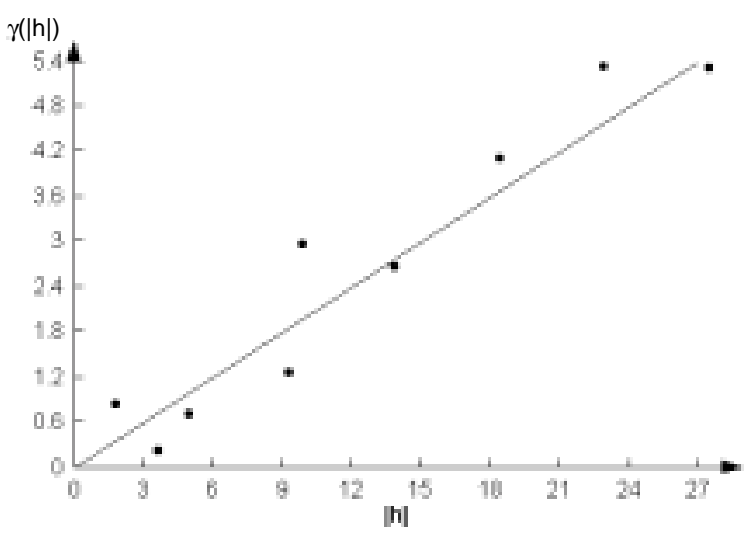

3 Jan 92

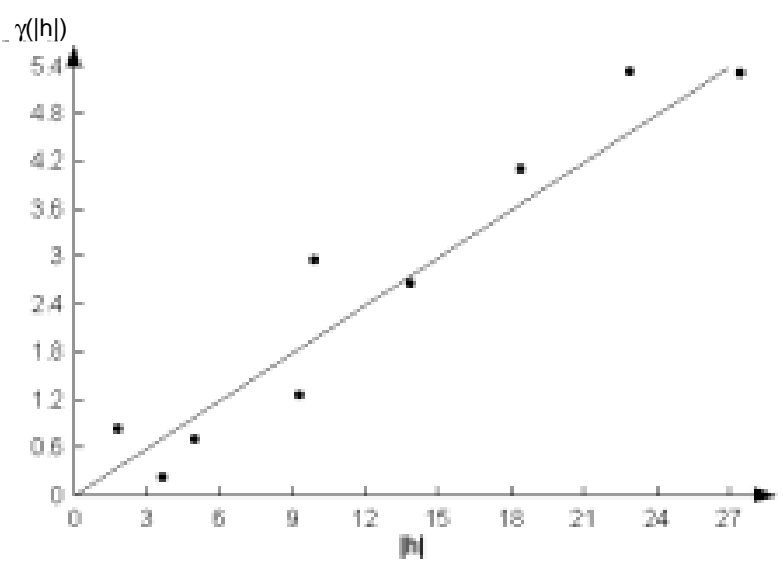

3 Jun 92

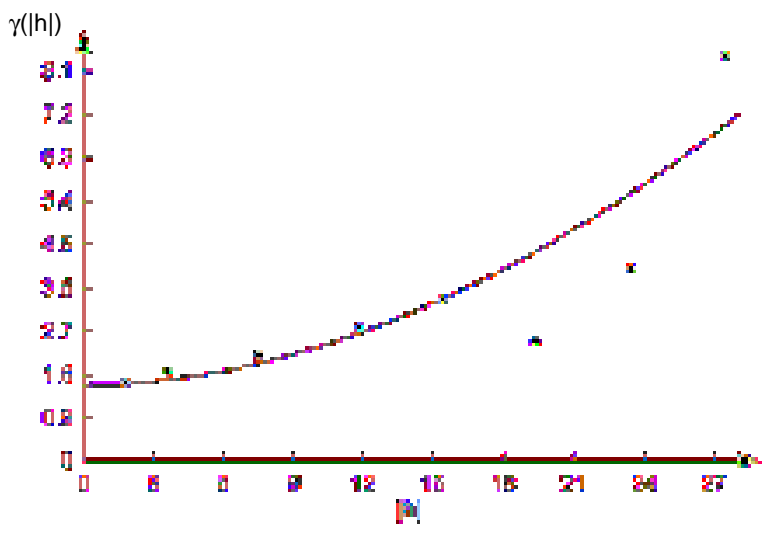

2 Jan 92

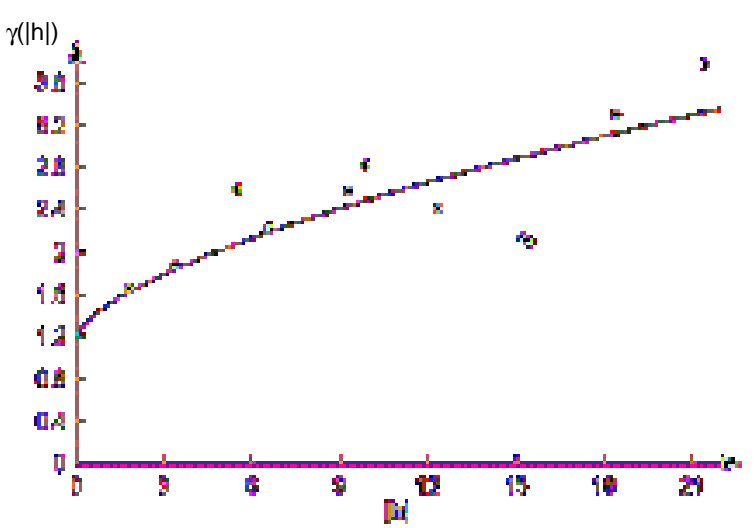

6 Jan 92

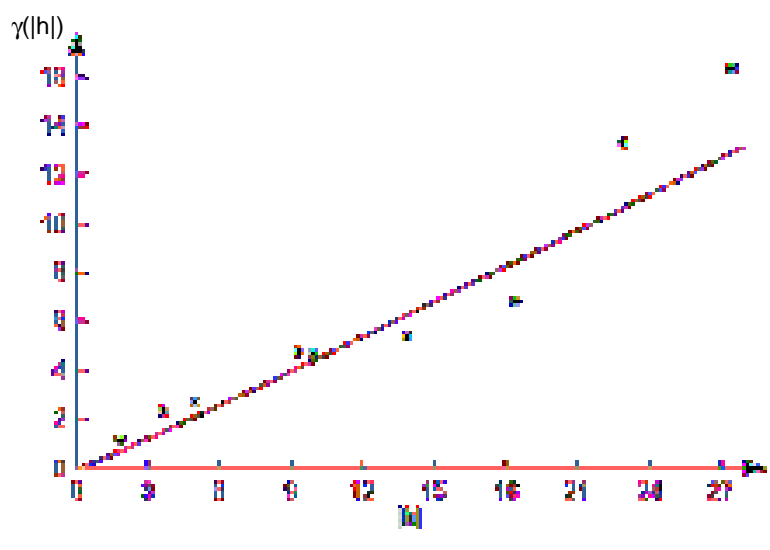

21 Jun 92 


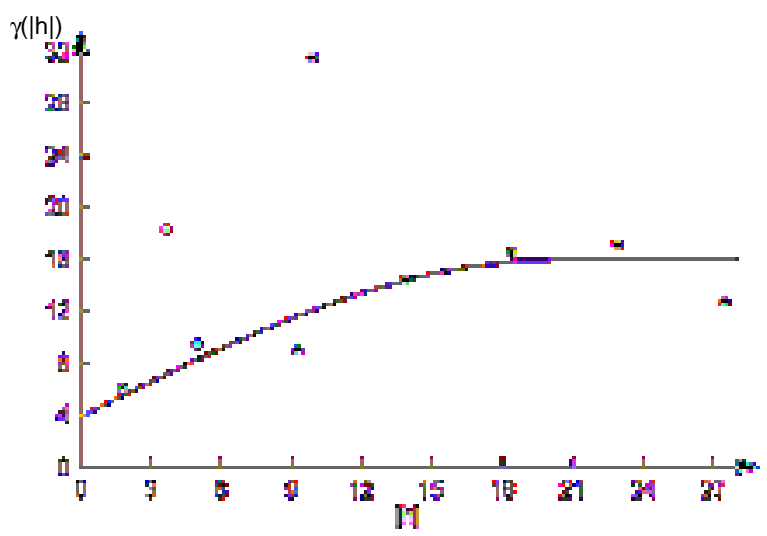

24 Jun 92

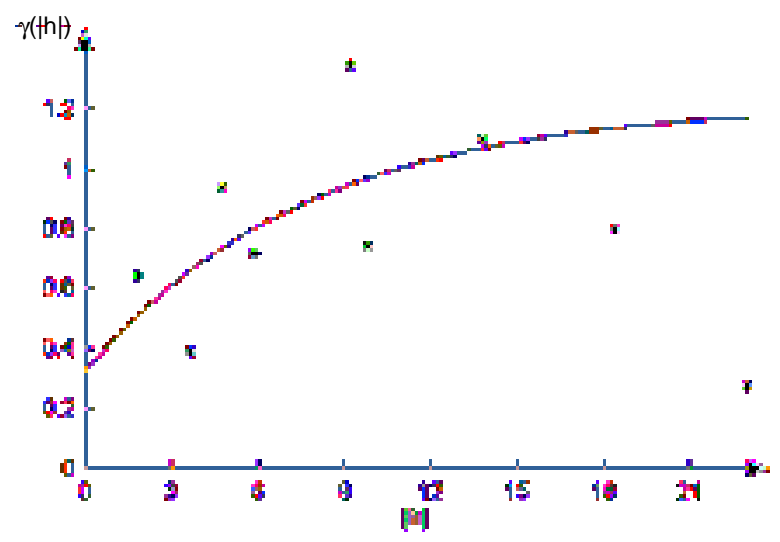

30 Jul 92

$\gamma(|\mathrm{h}|)$

III

31 Jul 92 


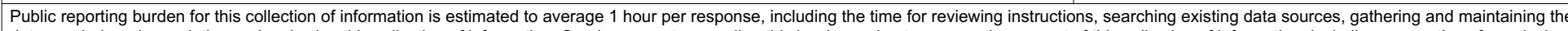

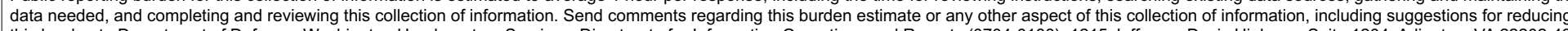

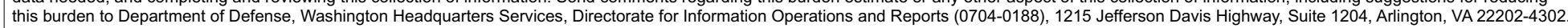

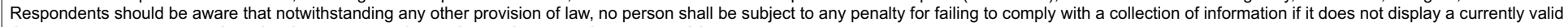
OMB control number. PLEASE DO NOT RETURN YOUR FORM TO THE ABOVE ADDRESS.
1. REPORT DATE (DD-MM-YY)
2. REPORT TYPE
January 2001
Technical Report

4. TITLE AND SUBTITLE

3. DATES COVERED (From - To)

5a. CONTRACT NUMBER

Spatial Analysis of Thaw Depth

5b. GRANT NUMBER

5c. PROGRAM ELEMENT NUMBER

6. AUTHOR(S)

5d. PROJECT NUMBER

Rosa T. Affleck and Sally A. Shoop

5e. TASK NUMBER

5f. WORK UNIT NUMBER

7. PERFORMING ORGANIZATION NAME(S) AND ADDRESS(ES)

8. PERFORMING ORGANIZATION REPORT NUMBER

U.S. Army Engineer Research and Development Center

Cold Regions Research and Engineering Laboratory

72 Lyme Road

Hanover, New Hampshire 03755-1290

ERDC/CRREL TR-01-1

9. SPONSORING/MONITORING AGENCY NAME(S) AND ADDRESS(ES)

10. SPONSOR / MONITOR'S ACRONYM(S)

Office of the Chief of Engineers

Washington, D.C. 20314

11. SPONSOR / MONITOR'S REPORT NUMBER(S)

\section{DISTRIBUTION / AVAILABILITY STATEMENT}

Approved for public release; distribution is unlimited.

Available from NTIS, Springfield, Virginia 22161.

13. SUPPLEMENTARY NOTES

\section{ABSTRACT}

Statistical and spatial analyses were performed on existing thaw-depth data sets from a variety of climatic and terrain conditions to determine the variability of thaw. These data include permafrost sites in Alaska, temperate sites in the continental United States in Minnesota and Wisconsin, and a large-scale, controlled test section with no solar input in the Frost Effects Research Facility (FERF) at the Cold Regions Research and Engineering Laboratory (CRREL) in Hanover, New Hampshire. Results can be used to spatially distribute soil properties based on point data or one-dimensional models, or to populate sparse data sets with terrain properties. They are also useful for analysis of impact of thaw distribution on predictive models, such as for predicting vehicle mobility.

\begin{tabular}{lll}
\hline 15. SUBJECT TERMS & \\
Freeze-thaw & Soil & Statistics \\
Ground & Spatial variability & Thaw depth
\end{tabular}

\begin{tabular}{|c|c|c|}
\hline \multicolumn{3}{|c|}{ 16. SECURITY CLASSIFICATION OF: } \\
\hline a. REPORT & b. ABSTRACT & c. THIS PAGE \\
\hline $\mathrm{U}$ & $\mathrm{U}$ & $\mathrm{U}$ \\
\hline
\end{tabular}

\begin{tabular}{|c|c|l|}
\begin{tabular}{|c|c|} 
17. LIMITATION OF \\
OF ABSTRACT
\end{tabular} & $\begin{array}{l}\text { 18. NUMBER } \\
\text { OF PAGES }\end{array}$ & 19a. NAME OF RESPONSIBLE PERSON \\
\cline { 3 - 3 } & 32 & 19b. TELEPHONE NUMBER (include area code) \\
$\mathrm{U}$ & 32 & \\
\hline
\end{tabular}

